Check for updates

Cite this: RSC Adv., 2020, 10, 14556

Received 17th January 2020

Accepted 2nd April 2020

DOI: $10.1039 / d 0 r a 00475 h$

rsc.li/rsc-advances

\section{Nitrogen-doped porous carbon from biomass with superior catalytic performance for acetylene hydrochlorination $\uparrow$}

\author{
Zhaobing Shen, ${ }^{a b}$ Yue Liu, ${ }^{b}$ Yejun Han, ${ }^{b}$ Yejun Qin, ${ }^{a}$ Jinhua Li, ${ }^{a}$ Ping Xing ${ }^{a}$ \\ and Biao Jiang (iD *ab
}

Acetylene hydrochlorination is an important aspect of the industrial synthesis of polyvinyl chloride, but it requires a toxic mercury chloride catalyst. Here we report a green, highly efficient and low cost nitrogen-doped soybean meal carbon (SBMC) catalyst obtained from the simple carbonization of biomass soybean meal (SBM) in the presence of zinc chloride. This material exhibits excellent catalytic performance during acetylene hydrochlorination, with an initial acetylene conversion greater than $99 \%$ and $98 \%$ selectivity for vinyl chloride at $200{ }^{\circ} \mathrm{C}$ over $110 \mathrm{~h}$. Analyses by X-ray photoelectron spectroscopy and temperature programmed desorption as well as catalytic activity evaluations show that pyridinic species are the active sites for hydrogen chloride, while pyrrolic $\mathrm{N}$ species are the main active sites for acetylene. An analysis of charge calculations based on model catalysts further indicates that the activity of pyrrolic $N$ species essentially determines the performance of the SBMC catalyst. This investigation of the mechanism of acetylene hydrochlorination over SBMC confirms that such nitrogendoped catalysts have two different active sites for the adsorption and activation of hydrogen chloride and acetylene molecules. This mechanism is different from that associated with metal chloride catalysts such as $\mathrm{HgCl}_{2}$. This SBMC catalyst is a potential alternative to $\mathrm{HgCl}_{2} @ A C$ catalysts for vinyl chloride synthesis and suggests a new means of designing carbon catalysts with basic surfaces for acetylene hydrochlorination.

\section{Introduction}

Polyvinyl chloride (PVC) is one of the most widely used plastics, with close to 41 million tons produced in 2016 and an annual growth in production of $5 \% .{ }^{1,2}$ In developing countries with rich coal reserves, acetylene hydrochlorination catalysed by mercuric chloride $\left(\mathrm{HgCl}_{2} @ \mathrm{AC}\right)$ is the primary process used to synthesize the vinyl chloride monomer (VCM) ${ }^{2,3}$ However, mercury is a potent toxin capable of causing cell death, brain damage and birth defects. ${ }^{4-6}$ Hence, more than 140 nations have agreed to a legally binding treaty related to the reduction of mercury release and use, signed in October 2013., ${ }^{7,8}$ The global Minamata Convention on Mercury ${ }^{9}$ came into effect on August 16, 2017 and has exerted significant pressure on the industrial production of acetylene-based PVC. Consequently, the research and development of mercury-free catalysts for PVC production

${ }^{a}$ Shanghai Green Chemical Engineering Research Centre, Shanghai Institute of Organic Chemistry, No. 345 Lingling Road, Shanghai, P. R. China. E-mail: jiangb@sioc.ac.cn ${ }^{b}$ Green Chemical Engineering Research Centre, Shanghai Advanced Research Institute, Chinese Academy of Sciences, No. 99 Haike Road, Zhangiiang Hi-Tech Park, Pudong, Shanghai, P. R. China

$\dagger$ Electronic supplementary information (ESI) available. See DOI: 10.1039/d0ra00475h and the sustainable development of the chlor-alkali industry are of considerable interest, and there has been extensive research in this field. Pioneering work and systematic studies performed by Hutchings and co-workers involving more than 30 metal chlorides showed that $\mathrm{AuCl}_{3}$ may be an alternative to $\mathrm{HgCl}_{2}$ based on its high activity. ${ }^{10-12}$ However, the cost of the noble metal gold and the rapid deactivation of this gold-based catalyst limit its practical applications. ${ }^{13}$

Carbon-based materials, particularly nitrogen-doped carbon, have recently received much attention as possible metal-free catalysts for acetylene hydrochlorination., ${ }^{1,2,14-21}$ Bao and coworkers reported that a nitrogen-doped SiC by vapor deposition method exhibited good catalytic performance for acetylene hydrochlorination, with an acetylene conversion $80 \%$ and selectivity to VCM over $98 \%$ at $200{ }^{\circ} \mathrm{C}$. Furthermore, they stated that carbon atoms bonded with pyrrolic $\mathrm{N}$ species were the active sites by DFT and experiments. ${ }^{2}$ Dai, Zhu and co-workers did widely studies of mercury-free catalysts and reported several nitrogen-doped carbon catalysts supported on AC, using cyanamide, melamine or aniline as doping precursors. These nitrogen-doped carbon catalysts exhibited improved catalytic activity compared with AC undoped. Furthermore, they demonstrated that pyridinic $\mathrm{N}$ and pyrrolic $\mathrm{N}$ maybe the active sites for hydrogen chloride and acetylene, and pore character 
effect on catalysis by experiment and DFT. ${ }^{17,19,20,22-25} \mathrm{Li}$ and coworkers also reported many works of mercury-free catalyst, including nitrogen-doped carbon catalyst for acetylene hydrochlorination. ${ }^{26}$ Jiang and co-workers reported the catalytic coupling reaction of acetylene and ethylene dichloride to synthesize VCM using nitrogen-doped activated carbon (AC) as the catalyst. Their results showed that nitrogen-doped AC not only catalyses acetylene hydrochlorination but also promote the dehydrochlorination of dichloroethane. ${ }^{1}$ In recent years, MOF and MOF-derived nitrogen-doped carbon materials were widely studied in supercapacitor and catalysis, especially for enhanced ORR performance. ${ }^{27,28}$ Moreover, Li et al. reported a number of metal-organic framework-derived nitrogen-doped carbon catalysts for acetylene hydrochlorination, and they demonstrated improved catalytic performance compared with AC. ${ }^{\mathbf{1 6 , 2 9 - 3 1}}$

Nitrogen-doped carbon as a metal-free catalyst exhibits its unique character including green, low-cost and good catalytic performance, which has been a research hotspot in mercuryfree catalyst for acetylene hydrochlorination. Even so, the study of nitrogen-doped carbon catalyst is still at an early stage, and is presently not sufficient for use in the industrial production of VCM. The prominent issue of nitrogen-doped carbon catalyst lies in its lower acetylene conversion and higher reaction temperature than metal catalyst, which motivates the further study for it. Furthermore, the manufacturing of such nitrogen-doped carbon materials usually involves the following characters, such as a complex synthesis processing, a nitrogen from external sources or the use of non-renewable carbon and nitrogen precursors. Thus, it is imperative to develop and scale up new methods of synthesizing highly efficient nitrogen-doped carbon catalysts through facile, green and low-cost routes. It would be even more desirable to develop these materials based on sustainable biomass resources.

Soybean meal (SBM) is a by-product of soybean oil extraction, and global SBM production is presently over one hundred million tons. Thus, this material represents a readily available, sustainable and inexpensive biomass. The crude protein content of soybean meal is as high as $30-50 \%$, suggesting significant potential as an excellent precursor for the synthesis of nitrogen-doped carbon materials.

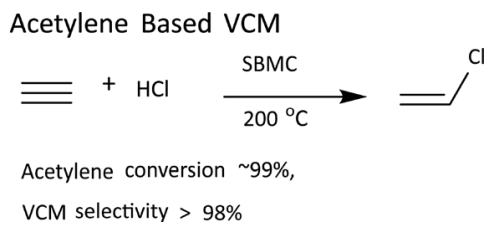

On this basis, the present work used SBM as a precursor to prepare nitrogen-doped porous SBM carbon (abbreviation SBMC) by a facile pyrolysis process (Fig. 1). The resulting SBMC exhibits superior catalytic performance, with an initial acetylene conversion of approximately $99 \%$ and greater than $98 \%$ selectivity for VCM at $200{ }^{\circ} \mathrm{C}$. Because SBM already contains a high level of nitrogen, preparation of the SBMC does not require an external nitrogen source, but rather is based simply on calcination of the SBM with $\mathrm{ZnCl}_{2}$ as dehydrating agent and pore former. These SBMC catalysts show good stability, with acetylene conversions from $99 \%$ to $97 \%$ during a $110 \mathrm{~h}$ test at $200{ }^{\circ} \mathrm{C}$. This material therefore has excellent potential as an alternative to $\mathrm{HgCl}_{2}$ as a catalyst for the acetylene-based VCM synthesis process. Moreover, on the basis of the previous works, ${ }^{2,19,20}$ this present work demonstrated that nitrogendoped mainly contributed to the catalytic activity of SBMC and nitrogen-doped carbon by the experiments, but not oxygendoped or defective carbon without nitrogen. Subsequently, the combination of catalytic reaction, XPS, TPD and charge calculation detailly stated that pyridinic $\mathrm{N}$ tended to adsorb and activate hydrogen chloride attributing to the alkalic and electron donor of pyridinic $\mathrm{N}$, and pyrrolic $\mathrm{N}$ preferred to adsorb and activate acetylene due to the positive charge on the pyrrolic N. This study inherits the previous works, further understanding the catalytic nature of nitrogen-doped carbon for acetylene hydrochlorination by experiments in detail.

\section{Results and discussion}

\section{Characterization of SBMC}

The SBMC (Fig. 1) was prepared by mixture of $\mathrm{ZnCl}_{2}$ and SBM, which calcined at $500,600,700$ or $800{ }^{\circ} \mathrm{C}$. $\mathrm{ZnCl}_{2}$ was removed by washing water. The elemental compositions of the original SBM and the SBMC specimens were determined by combustionbased elemental analysis, X-ray photoelectron spectroscopy (XPS) and inductively coupled plasma mass spectrometry (ICPMS). The results were summarized in Table 1 . It can be seen that the SBMC yields at the different carbonization temperatures were all high (over $30 \%) .{ }^{33}$ It is also apparent that there were no variations in the elemental compositions of the SBMC processed at the different temperatures. These results indicate that the carbonization of the SBM was essentially complete even when using the relatively low temperature of $500{ }^{\circ} \mathrm{C}$ for $2 \mathrm{~h}$, as a result of the presence of $\mathrm{ZnCl}_{2}$. Comparing the elemental analysis data for the SBM and the SBMC-600, it is apparent that more $\mathrm{H}$ and $\mathrm{O}$ was lost during calcination as compared with $\mathrm{C}$ and $\mathrm{N}$. This difference is attributed to the dehydration reaction that occurs when using $\mathrm{ZnCl}_{2}$ as an activating agent at $600{ }^{\circ} \mathrm{C}$. The loss of $\mathrm{C}, \mathrm{H}, \mathrm{N}$ and $\mathrm{O}$ facilitated the formation of a porous/ defective structure in the SBM during carbonization. The XPS, used to measure the atoms on the surface of material, results showed higher N/C ratio and lower $\mathrm{O} / \mathrm{C}$ ratio on the surface of SBMC than the data by the combustion elemental analysis measurement, which indicated that the dehydration reaction was higher efficient on the surface of SBM than in the interior when using $\mathrm{ZnCl}_{2}$ in the carbonization process. The higher content of N/C showed that there was much more nitrogendoped carbon and defective structure on the surface of SBMC, more contributing to the catalytic performance. In addition, the $\mathrm{N} / \mathrm{C}$ and $\mathrm{O} / \mathrm{C}$ ratios in the SBMC specimens by XPS were almost constant, and thus they were evidently unaffected by variations in the carbonization temperature $500-800{ }^{\circ} \mathrm{C}$. The ICP-MS results demonstrate the presence of trace amounts of metal ion in the SBMC samples, even after repeated washing of the crude products with dilute hydrochloric acid and deionized water with the intent of reducing the negative effects of ions 

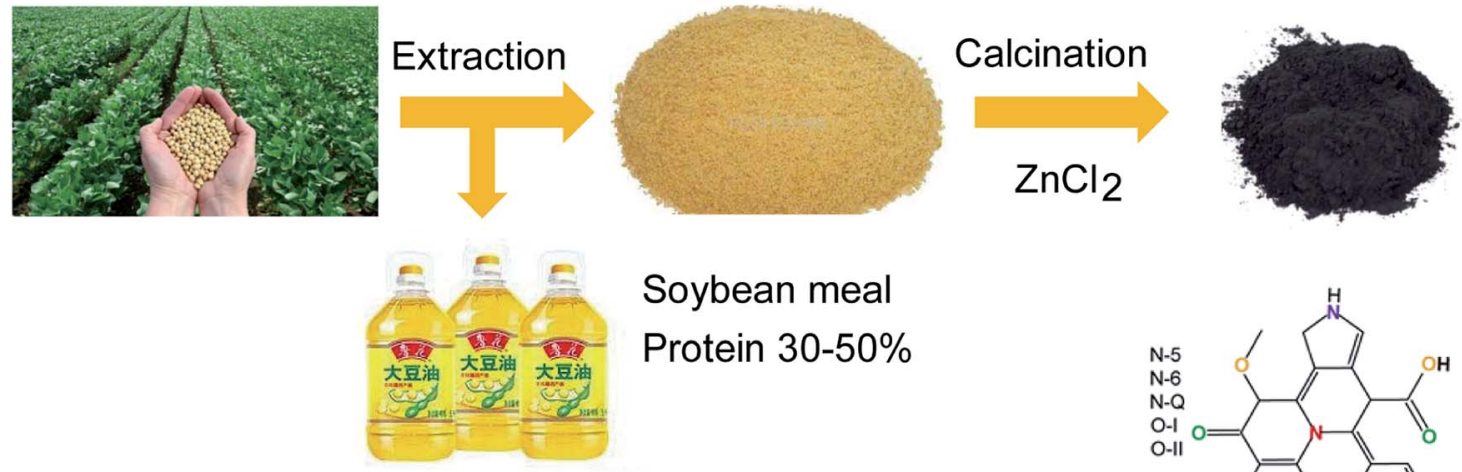

Soybean meal Protein $30-50 \%$

\section{Soybean oil}

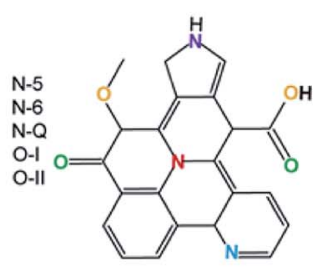

Fig. 1 The synthesis of nitrogen-doped porous carbon from soybean meal bio-waste. ${ }^{32}$

such as $\mathrm{Ca}^{2+}$ and $\mathrm{K}^{+}$. The residual $\mathrm{Zn}^{2+}$ from the activation agent was present only at very low levels.

The general structures, sizes and morphologies of the SBMC specimens were assessed using atomic force microscopy (AFM), scanning electron microscopy (SEM) and high-resolution transmission electron microscopy (HRTEM), as shown in Fig. 2. The AFM images demonstrate that the SBM and SBMC600 were comprised of irregularly shaped particles, indicating that carbonization had no effect on the morphology. The 3D images in this figure also show irregular shapes for both materials (insets to Fig. 2a and b). The SEM image of the SBMC indicates irregularly shaped particles with smooth surfaces (Fig. 2c) and a large number of continuous mesopores and macropores along the cross section (inset to Fig. $2 \mathrm{c}$ and $\mathrm{f}$ ). The pores had irregular shapes and diameters ranging from $\sim 100 \mathrm{~nm}$ to $\sim 2 \mu \mathrm{m}$. These pores can be attributed to various synergistic effects, including etching and swelling as well as the template effect of the $\mathrm{ZnCl}_{2}$. Zinc chloride could catalyze the dehydration and condensation reactions in SBM, and also acted as a pore former and template during the carbonation process, all contributing to the formation of porous carbon material. It was reported that the impregnation of $\mathrm{ZnCl}_{2}$ played an important role in increasing specific surface area and generation of micropores. The impregnation of $\mathrm{ZnCl}_{2}$ acts as a skeleton and template and occupies a volume, inhibiting the contraction of the particle during the carbonization, which can leave porosity structure after being washed off with deionized water. ${ }^{34,35}$ In addition, the energy dispersive X-ray spectroscopy (EDX) maps (Fig. 2g-i) indicate uniform distributions of carbon, nitrogen and oxygen throughout the SBMC-600. The SBMC microstructure was further analysed by TEM (Fig. 2d) and HRTEM (Fig. 2e). The resulting images show that the material contained both amorphous carbon and graphite, with numerous nanopores. The corresponding selected area electron diffraction (SAED) pattern (inset to Fig. 2e) exhibits diffraction rings that confirm the amorphous nature of this material, which had a turbostratic structure.

$\mathrm{N}_{2}$ adsorption/desorption isotherms were obtained to characterize the pore structures (Fig. 3a and b). Fig. 3a demonstrates that the SBMC materials generated a combination of types I and

Table 1 Yields of the SBMC samples and the elemental compositions of the SBM and SBMC

\begin{tabular}{|c|c|c|c|c|c|c|c|c|c|c|c|c|c|c|}
\hline \multirow[b]{2}{*}{ Sample } & \multirow[b]{2}{*}{ Yield $^{a}(\%)$} & \multicolumn{4}{|c|}{$\begin{array}{l}\text { Chemical composition }{ }^{b, c} \\
\text { (at\%) }\end{array}$} & \multicolumn{2}{|c|}{ Mole ratio $^{d}$} & \multicolumn{7}{|c|}{ Chemical composition $^{e}(\mathrm{ppm})$} \\
\hline & & $\mathrm{C}$ & $\mathrm{H}$ & $\mathrm{N}$ & $\mathrm{O}$ & $\mathrm{N} / \mathrm{C}$ & $\mathrm{O} / \mathrm{C}$ & $\mathrm{Ca}$ & $\mathrm{K}$ & $\mathrm{Mg}$ & $\mathrm{Zn}$ & $\mathrm{Al}$ & $\mathrm{Fe}$ & $\mathrm{Na}$ \\
\hline SBM & - & 42.4 & 6.3 & 7.2 & 37.2 & 0.17 & 0.88 & 129.6 & 411.6 & 93.1 & 2.4 & 8.7 & 12.4 & 2.6 \\
\hline SBMC-500 & 30.8 & 63.4 & 3.8 & 6.8 & 15.6 & 0.11 & 0.25 & 1.6 & 0.3 & 0.2 & 62.8 & 0.4 & 0.6 & 0.2 \\
\hline SBMC-600 & 34.8 & 72.6 & 3.2 & 6.9 & 7.8 & 0.10 & 0.11 & 0.9 & 0.3 & 0.2 & 73.7 & 1.1 & 1.1 & 0.2 \\
\hline SBMC-700 & 31.8 & 63.5 & 3.3 & 7.0 & 16.4 & 0.11 & 0.26 & 2.2 & 0.4 & 0.3 & 83.8 & 1.3 & 2.6 & 0.4 \\
\hline SBMC-800 & 33.1 & 65.0 & 3.3 & 6.5 & 14.7 & 0.10 & 0.23 & 1.9 & 2.0 & 0.8 & 127.6 & 2.6 & 9.5 & 0.3 \\
\hline SBMC-500 & - & 72.0 & - & 12.1 & 15.9 & 0.14 & 0.17 & - & - & - & - & - & - & - \\
\hline SBMC-600 & - & 77.3 & - & 8.9 & 13.7 & 0.10 & 0.13 & - & - & - & - & - & - & - \\
\hline SBMC-700 & - & 74.2 & - & 12.6 & 13.2 & 0.15 & 0.13 & - & - & - & - & - & - & - \\
\hline SBMC-800 & - & 75.7 & - & 11.3 & 13.0 & 0.13 & 0.13 & - & - & - & - & - & - & - \\
\hline Loss of SBMC- $600^{f}$ & - & 40.4 & 82.3 & 26.5 & 92.7 & & & - & - & - & - & - & - & - \\
\hline
\end{tabular}

${ }^{a}$ Calculated from the mass ratio of the obtained carbon to its precursor. ${ }^{b}$ Measured by combustion elemental analyses, line 1 -line $5 .{ }^{c}$ Calculated using the XPS data for $\mathrm{C}, \mathrm{N}$ and O, line 6 -line $9 .{ }^{d}$ Calculated by ratioing moles of $\mathrm{N}$ and $\mathrm{O}$ to $\mathrm{C} .{ }^{e}$ Based on data from ICP-MS. ${ }^{f}$ Calculated from the chemical composition data for SBM and SBMC-600. 
IV isotherms according to the IUPAC classification system. High adsorption capacities at low relative pressures $\left(P / P_{0}<0.1\right)$ were observed, indicating the presence of a significant quantity of micropores. Type $\mathrm{H} 4$ hysteresis loops caused by capillary condensation at $P / P_{0}$ values ranging from 0.4 to 1 were also observed, suggesting the presence of mesopores as well. Notably, the adsorption capacity increased with increases in the carbonization temperature from 500 to $700{ }^{\circ} \mathrm{C}$ but then decreased at $800{ }^{\circ} \mathrm{C}$. These results show that the SBMC synthesized at a relatively high temperature had a distinct surface area and volume. The properties at intermediate temperatures likely resulted from the accelerated reaction between the carbon precursor and the $\mathrm{ZnCl}_{2}$, leading to higher porosity and enlarged pores. In contrast, the carbon skeleton was destroyed and collapsed by the action of the $\mathrm{ZnCl}_{2}$ at $800{ }^{\circ} \mathrm{C} . .^{36,37}$ The pore size distributions of these materials are summarized in Fig. 3b. It is evident that micropores and a smaller quantity of mesopores (with sizes ranging from 0.5 to $3.5 \mathrm{~nm}$ ) were present, consistent with the results in Fig. 2a. Table 2 summarizes the textural parameters of the SBMC. As the carbonization temperature was increased from 500 through 600 to $700{ }^{\circ} \mathrm{C}$, the specific surface area and pore volume increased dramatically, from 739 to 1038 and $1124 \mathrm{~m}^{2} \mathrm{~g}^{-1}$ and from 0.31 to 0.46 to $0.52 \mathrm{~cm}^{3} \mathrm{~g}^{-1}$, respectively. However, the specific surface area and pore volume all decreased when the temperature was raised to $800{ }^{\circ} \mathrm{C}$. These variations in textural parameters with carbonization temperature are in agreement with the adsorption capacity data (Fig. 3a and b). The observed increases in specific surface area can be primarily ascribed to the formation of mesopores by the $\mathrm{ZnCl}_{2}$. The fraction of the specific surface area contributed by mesopores increased from 0.28 to $0.51,0.28$ and 0.45 as the temperature was increased. Similarly, the contributions of the mesopore volume to the total pore volume increased from 0.29 to $0.52,0.35$ and 0.48 with increasing temperature.

$\mathrm{X}$-ray diffraction (XRD) patterns were used to investigate the structures of the SBMC prepared at different carbonization temperatures (Fig. 3c). Two diffraction peaks were observed at $\sim 25.5^{\circ}$ and $\sim 43.5^{\circ}$ corresponding to the (002) and (100) planes of graphite, respectively. It was notable that the diffraction peak at $\sim 25.5^{\circ}$ was relatively sharp and narrow, indicating a certain degree of graphitization of the SBMC synthesized at $500-800{ }^{\circ} \mathrm{C}$. As the temperature was increased from 600 through 700 to $800{ }^{\circ} \mathrm{C}$, peaks appeared at $\sim 43.5^{\circ}$, demonstrating that (100) graphite planes were formed in the SBMC. However, the resulting SBMC produced at all carbonization temperatures generally had an amorphous structure with a relatively low degree of graphitization, in agreement with the HRTEM images in Fig. 2e. This result can likely be attributed to the local lattice distortion caused by heteroatom ( $\mathrm{N}$ and $\mathrm{O}$ ) doping. It was also
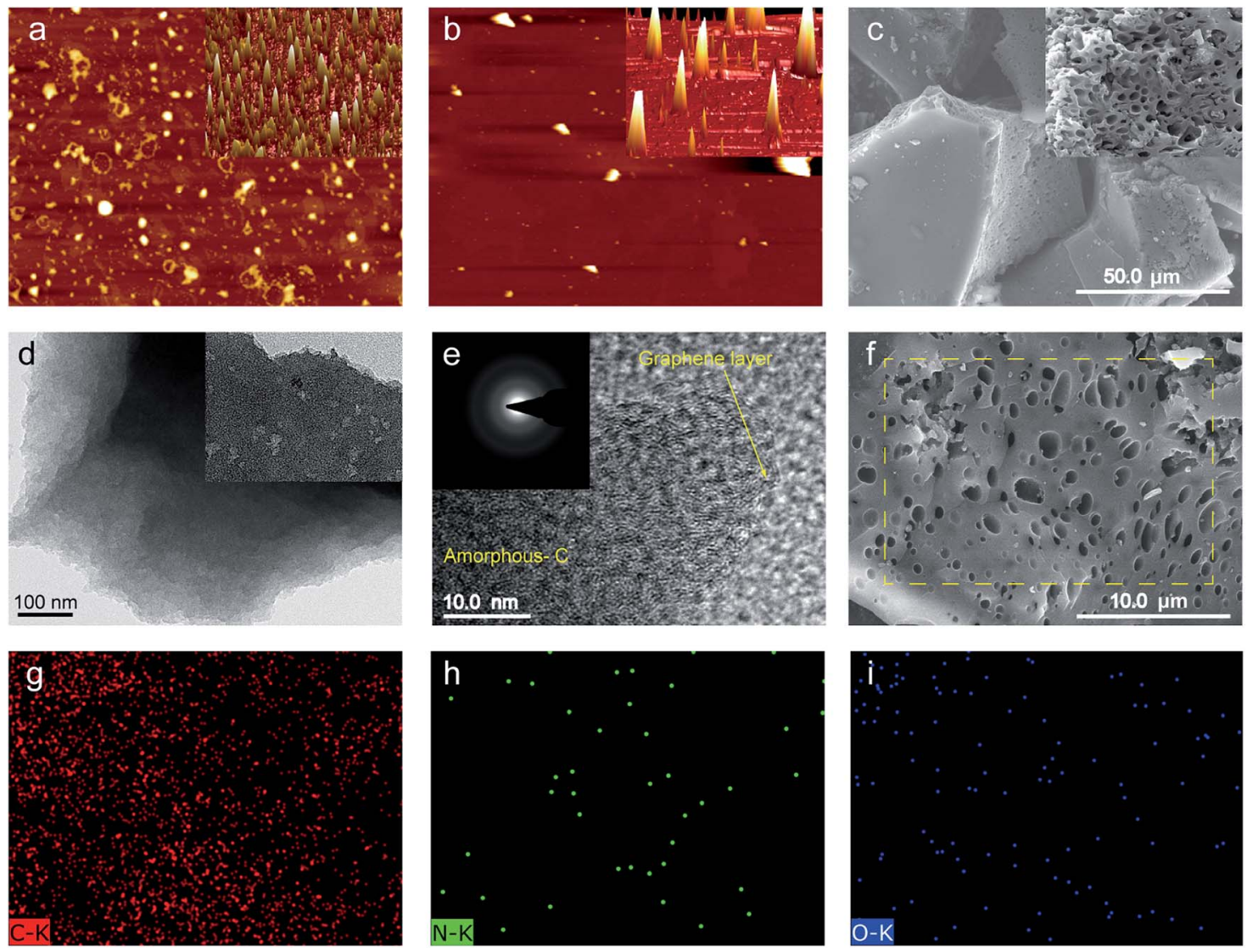

Fig. 2 The 2D AFM images of (a) the SBM (inset: 3D image) and (b) the SBMC-600 (inset: 3D image). (c) SEM image of the SBMC-600 (inset: SEM image). (d) TEM image of the SBMC-600 (inset: TEM image). (e) High-resolution TEM image of the SBMC-600 (inset: SAED pattern). (f) Highpowered SEM image of the SBMC-600 and the corresponding EDX maps for (g) C, (h) N and (i) O. 
observed that the abundant pores formed by the activation reaction not only led to a breakdown of aligned structural domains in the SBMC, but also disturbed the stacking periodicity of the graphitic carbon structure..$^{38,39}$

The Raman spectra of the SBMC are shown in Fig. 3d. The peaks at $1353 \mathrm{~cm}^{-1}$ (the D band) and $1585 \mathrm{~cm}^{-1}$ (the $\mathrm{G}$ band) reflect disordered $\mathrm{sp}^{3} \mathrm{C}$ atoms/defective graphitic structures and ordered carbon structures with $\mathrm{sp}^{2} \mathrm{C}$ atoms/crystalline graphite, respectively, and can be used to confirm the amorphous structure of the SBMC. ${ }^{40}$ The degree of graphitization is usually estimated based on the ratio of the D-band to the Gband $\left(I_{\mathrm{D}} / I_{\mathrm{G}}\right)$, although this ratio is also significantly affected by both the nitrogen content and the presence of coupled molecular pores and edge terminations. ${ }^{\mathbf{4 1}}$ With increases in the carbonization temperature, the value of $I_{\mathrm{D}} / I_{\mathrm{G}}$ gradually became lower (Fig. 3d), implying increased graphitization of the SBMC, consistent with the XRD patterns (Fig. 3c).

XPS data were acquired to assess the surface elemental compositions and configurations of doped heteroatoms in the SBMC (Fig. 4). Fig. 4a demonstrates three characteristic peaks observed at $\sim 284, \sim 400$ and $\sim 531 \mathrm{eV}$, which can be assigned to $\mathrm{C} 1 \mathrm{~s}, \mathrm{~N} 1 \mathrm{~s}$ and $\mathrm{O} 1 \mathrm{~s}$ signals, respectively. These results indicate that nitrogen and oxygen atoms were successfully doped into the carbon-based structure of the SBMC, to a greater extent than observed in the case of nitrogen-doped carbon catalysts (NAC) by post-treatment organic nitrogen processing. ${ }^{1,2,17,19}$ The highresolution XPS C 1s spectra of the SBMC-600 (Fig. 4b) can be deconvoluted into four individual peaks corresponding to $\mathrm{C}-\mathrm{C}$ (284.5 eV), C-N (285.2 eV), C-O (286.3 eV) and $\mathrm{C}=\mathrm{O}(288.3 \mathrm{eV})$, further confirming the successful incorporation of nitrogen and oxygen into the carbon framework, consistent with the results shown in Fig. 4a. ${ }^{1}$ The high-resolution $\mathrm{O}$ 1s spectrum in Fig. $4 \mathrm{c}$ clearly establishes the presence of several oxygen-based groups, including quinone-type $\mathrm{C}=\mathrm{O}(\mathrm{O}-\mathrm{I})$ and phenol-type $\mathrm{C}-\mathrm{OH}(\mathrm{O}-$ II), which might have a positive effect on catalytic performance during acetylene hydrochlorination. ${ }^{\mathbf{1 3 , 4 2}}$ The highresolution $\mathrm{N}$ 1s spectrum of the SBMC-600 was acquired to gain further insights into the extent of nitrogen doping. As shown in Fig. $4 \mathrm{~d}$, the deconvolution of the high-resolution $\mathrm{N}$ 1s spectrum produced three peaks corresponding to pyridinic $\mathrm{N}(398.6 \mathrm{eV})$, pyrrolic $\mathrm{N}(400.2 \mathrm{eV})$ and graphitic $\mathrm{N}(401.2 \mathrm{eV})$. The molecular structure of the SBMC suggested by these data is provided in Fig. 4e. Bao and co-workers previously reported that carbon atoms bond with pyrrolic $\mathrm{N}$ species to produce active sites for acetylene hydrochlorination, based on both experimental and theoretical studies. ${ }^{2}$ Dai, Jiang and other researchers have determined that pyridinic $\mathrm{N}$ and carbon atoms bonded to such species represent active sites, based on both experiments and density functional theory calculations., ${ }^{\mathbf{1 1 9 , 2 0}}$

The Fourier transform infrared (FTIR) spectra of the SBM and the SBMC prepared at different carbonization temperatures are provided in Fig. 4f. After carbonization at $500-800{ }^{\circ} \mathrm{C}$, the obtained SBMC exhibited very similar spectra to that of the raw SBM. This result suggests that the surface functional groups of the SBMC remained the same before and after carbonization. Both the SBMC and SBM exhibited characteristic $\mathrm{O}-\mathrm{H}$ and $\mathrm{N}-\mathrm{H}$ stretching vibration peaks at $\sim 3405$ and $\sim 3285 \mathrm{~cm}^{-1}$ as well as a C-H stretching peak at $\sim 2900 \mathrm{~cm}^{-1}$. The characteristic absorption bands of aromatic $\mathrm{CN}$ heterocycles were also observed in the range of $\sim 1280$ to $\sim 1605 \mathrm{~cm}^{-1} .{ }^{43}$ These data imply that the local structure of these carbon materials comprised CN units, consistent with the XPS analysis. Together, the data demonstrate the unique features of SBMC, such as high specific surface areas and pore volumes and significant heteroatom doping.
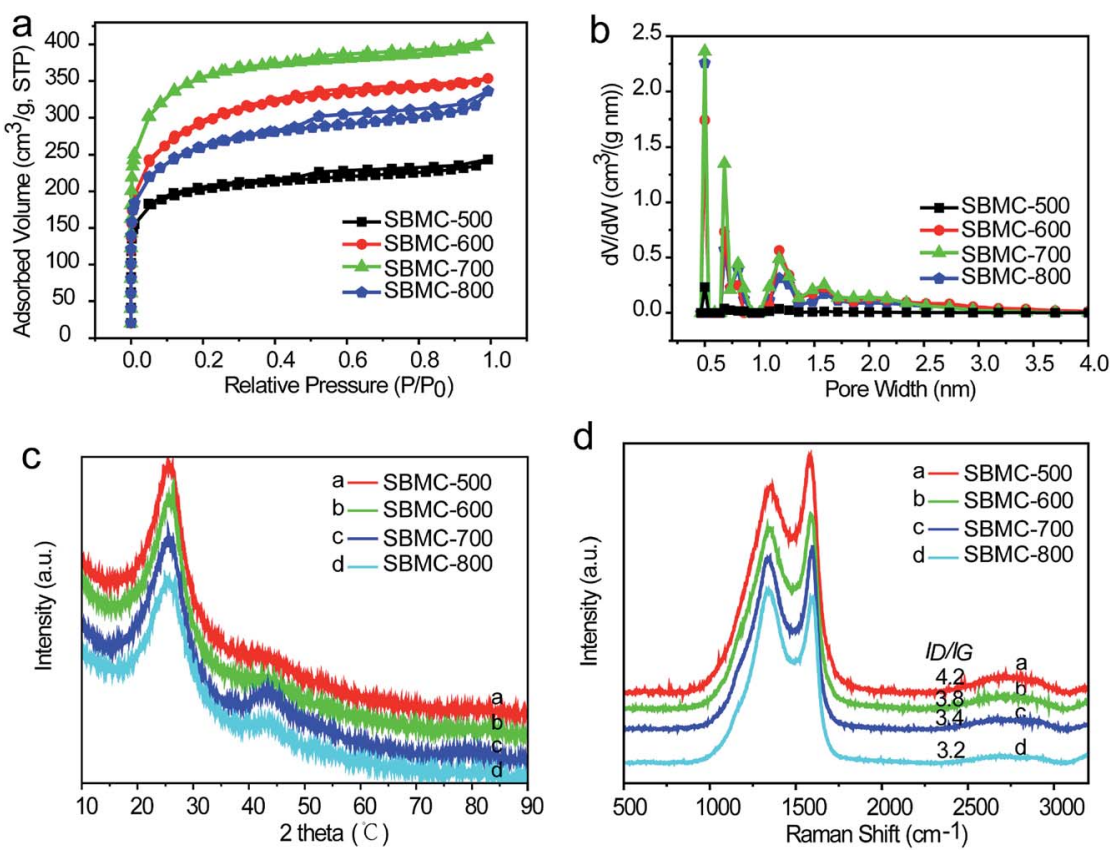

Fig. 3 The structural characterization of SBMC specimens synthesized by carbonization at different temperatures. (a) $\mathrm{N}_{2}$ adsorption-desorption isotherms, (b) pore size distributions, (c) X-ray diffraction patterns and (d) Raman spectra. 


\section{Catalytic performance of SBMC}

The relationships between the catalytic activities of the SBMC and processing parameters including carbonization temperature, $\mathrm{ZnCl}_{2}$ concentration, reaction temperature and gas hourly space velocity (GHSV) of $\mathrm{C}_{2} \mathrm{H}_{2}$ were examined, as shown in Fig. $5 \mathrm{a}-\mathrm{e}$. The use of AC gave an acetylene conversion of just $30 \%$ at $200{ }^{\circ} \mathrm{C}$, atmospheric pressure and a space velocity of 30 $\mathrm{h}^{-1}$, while SBM-800 was prepared by simply calcination of SBM at $800{ }^{\circ} \mathrm{C}$ without addition $\mathrm{ZnCl}_{2}$ and showed $\sim 40 \%$ conversion of acetylene under the same reaction conditions (Fig. 5a). Although the AC had a high specific surface area of $\sim 997 \mathrm{~m}^{2}$ $\mathrm{g}^{-1}$, it showed a lower acetylene conversion than the SBM-800, which had an area of only $19.9 \mathrm{~m}^{2} \mathrm{~g}^{-1}$ (Table 2). The superior performance of the latter material is attributed to the bonds between carbon and nitrogen species. ${ }^{\mathbf{1 , 2 , 1 9 , 2 0}}$ As shown in Fig. 5a, the SBMC synthesized at 500 or $600{ }^{\circ} \mathrm{C}$ in conjunction with $\mathrm{ZnCl}_{2}$ exhibited excellent performance, giving an initial acetylene conversion of $\sim 99.5 \%$ at $200{ }^{\circ} \mathrm{C}$, atmospheric pressure and a gas hourly space velocity of $30 \mathrm{~h}^{-1}$, without any obvious inactivation after $10 \mathrm{~h}$. The SBMC obtained at 700 and $800{ }^{\circ} \mathrm{C}$ gave an initial acetylene conversion as high as $\sim 98 \%$ but showed reduced stability. As shown in Table 2, it was found that the data of the specific area and nitrogen contents of SBMC-700 and SBMC-800 was almost same as them of SBMC-500 and SBMC-600, which implied that the reduced stability of SBMC700 and SBMC-800 had nothing to do with the catalysts themselves and carbonization temperature. Besides, Zhu et al. reported that nitrogen-doped carbon catalyst had excellent catalytic performance at $900-1100{ }^{\circ} \mathrm{C}$, which further demonstrated that high carbonization temperature didn't have negative effect on the catalytic activity of nitrogen doped carbon. ${ }^{23}$ The above result implied that the other key factor of $\mathrm{ZnCl}_{2}$ residual might be negative for the catalytic performance. As shown in Table 1, the data of $\mathrm{ZnCl}_{2}$ residual in SBMC-700 and SBMC-800 was higher than that of SBMC-500 and SBMC-600. To demonstrate it, SBMC-800 was immersed in 10\% (v/v) hydrochloric acid at $50{ }^{\circ} \mathrm{C}$ for $12 \mathrm{~h}$, washed with deionized water then dried at $70{ }^{\circ} \mathrm{C}$. As shown in Fig. 5c, the repeatedly washed SBMC-800 exhibited very excellent catalytic performance and stability, with a conversion of acetylene over $98 \%$ in $10 \mathrm{~h}$, which strongly stated that the $\mathrm{ZnCl}_{2}$ residual was a critical parameter in preparation of nitrogen doped carbon catalysts. In fact, a high carbonization temperature has no negative influence on catalytic performance of SBMC, but it might make $\mathrm{ZnCl}_{2}$ difficult to remove completely. To compare to the SBMC, a material termed NAC-800 was prepared using AC and acrylamide as the carbon and nitrogen precursors, respectively, at a mass ratio of acrylamide to AC $1: 1$, using a post-treatment technology. The NAC-800 exhibited only $70 \%$ conversion of acetylene under the same reaction conditions, which was attributed to the high loss percentage and low dispersion of nitrogen atoms during the post-treatment process. Comparing the catalytic performances of the SBMC and the NAC-800 highlights the advantages of the combination of high carbon and nitrogen levels in the SBMC, which ensures improved nitrogen distribution and lower losses.
The effects of the $\mathrm{ZnCl}_{2}$ amount on the catalytic activities of the SBMC were investigated (Fig. 5b). It was found that the catalytic activity was significantly increased when using $\mathrm{ZnCl}_{2}$ as an activating agent and dehydrate agent (Fig. 5a). In a further set of experiments, materials termed SBMC-1Zn-600, SBMC2Zn-600 and SBMC-3Zn-600 were prepared, with $\mathrm{ZnCl}_{2}$ to SBM mass ratios of 1.0, 2.0 and 3.0, respectively. As shown in Fig. 5b, increasing the level of $\mathrm{ZnCl}_{2}$ relative to the SBM decreased the catalytic activity. The SBMC-1Zn-600 gave an acetylene conversion greater than $97 \%$ and showed significant stability at $200{ }^{\circ} \mathrm{C}$, while the SBMC-2Zn-600 and SBMC-3Zn-600 both showed poor catalytic activity and stability. There was no obvious correlation between $\mathrm{ZnCl}_{2}$ adding amount and catalytic performance, implying that traces of residual $\mathrm{ZnCl}_{2}$ might poison the SBMC. Similarly, the SBMC-800 exhibited a poisoning phenomenon (Fig. 5a) and was confirmed by the extra experiment (Fig. 5c). To confirm the effect of residual $\mathrm{ZnCl}_{2}$ on catalytic activity, samples of SBMC-2Zn-600, SBMC$3 Z n-600$ were washed by the same method as that of SBMC800. As shown in Fig. 5c, the catalytic performance and stability of each material was obviously increased, indicating the toxicity of the residual $\mathrm{ZnCl}_{2}$. So, the suitable dosage of $\mathrm{ZnCl}_{2}$ is beneficial for the catalytic performance and preparation cost.

In contrast to mercuric chloride which is prone to sublimation under high temperature, i.e., 200 or $220^{\circ} \mathrm{C}$, this catalyst is rather robust. It can be operated at an even higher temperature and space velocity, as shown in Fig. $5 \mathrm{~d}$ and e, respectively. For example, at $220{ }^{\circ} \mathrm{C}$ and $50 \mathrm{~h}^{-1}$ the conversion of acetylene reached $95 \%$ and the selectivity to VCM remained above $98 \%$. Furthermore, the SBMC-600 exhibited good stability, such that the conversion of acetylene only decreased slightly during a $110 \mathrm{~h}$ test at $200{ }^{\circ} \mathrm{C}$, as demonstrated in Fig. $5 \mathrm{f}$.

To compare this work with the previous works in the literatures at the similar conditions, the space-time yield of VCM $\left(\mathrm{STY}_{\mathrm{VCM}}\right)$ were calculated in Fig. 6a. To get the reliable result, this work was carried out on the similar conditions as the literatures, i.e., at 180,200 , and $220^{\circ} \mathrm{C}$. As shown in Fig. 6a, the value of $\mathrm{STY}_{\mathrm{VCM}}$ in this work was higher than the most results from the references, which sated the superior catalytic performance of SBMC. But the value of STY $\mathrm{VCM}_{\mathrm{M}}$ in this work was little lower than TPPB@SAC and NC-2 in the literature. TPPB@SAC is a ionic liquid derived metal-free catalyst and NC-2 is a macroporous nitrogen-doped carbon catalyst. Furthermore, the deactivation rate of SBMC was compared with the works in the literatures in Fig. 6b. As shown in Fig. 6b, SBMC exhibited a very low deactivation rate, obviously lower than TPPB@SAC and NC2. In a word, by contrast with $\mathrm{STY}_{\mathrm{VCM}}$ and deactivation rate between SBMC and the works in the literatures, it was seen that SBMC exhibited superior catalytic performance for acetylene hydrochlorination.

To further understand the nature of the catalysts, the value of $\mathrm{STY}_{\mathrm{VCM}}$ was normalized by the specific area and nitrogen contents (Fig. 6c). It was found that the value of normalized STY $_{\text {VCM }}$ was almost lower than all the values from the literatures, which implied that the excellent catalytic performance of SBMC was mainly limited by the combined action of specific 
area and nitrogen content. This result also indicated that there was no extra catalytic active site on SBMC different from the common nitrogen doped carbon. In contrast, the $\mathrm{STY}_{\mathrm{VCM}}$ value of TPPB@SAC and NC-2 further encourage us to optimize SBMC by introducing the innovative active sites and macroporous pores.

\section{Catalytic sites and acetylene hydrochlorination mechanism}

In the past, there have been many efforts by various research groups to investigate the active sites of nitrogen-doped carbon materials during acetylene hydrochlorination, on the basis of both experimental and theoretical work. Bao et al. indicated that acetylene is only minimally absorbed on quaternary and pyridinic $\mathrm{N}$ sites because of the endothermic nature of the adsorption process. They suggested that carbon doped with pyrrolic $\mathrm{N}$ species could catalyse the hydrochlorination of acetylene. ${ }^{2}$ Dai et al. reported that hydrogen chloride is absorbed on $\mathrm{g}-\mathrm{C}_{3} \mathrm{~N}_{4}$ via $\mathrm{H}$ atoms near pyridinic $\mathrm{N}$ atoms, while acetylene is adsorbed by carbon atoms bonded to pyridinic and graphitic $\mathrm{N}$ atoms. ${ }^{20}$ Wang et al. found that the active sites in PSAC-N comprise quaternary nitrogen atoms bonded between two 6-membered rings. ${ }^{19}$ Zhang et al. demonstrated that the order of importance of nitrogen species in acetylene hydrochlorination was: pyrrolic $\mathrm{N}>$ graphitic $\mathrm{N}>$ pyridinic $\mathrm{N} .{ }^{17}$ However, the role of different $\mathrm{N}$ species in providing active sites is still being debated. It is critical to identify the active sites in SBMC during acetylene hydrochlorination to allow for further optimization of the catalyst. However, the coexistence of different $\mathrm{N}$ and $\mathrm{O}$ species in these materials makes it very difficult to assess their respective catalytic roles.

The effects of defective carbon on the catalytic performance of SBMC could also be important. The protein, crude fibre and nitrogen in SBM could all be degraded to produce low molecular substances through pyrolysis. These new compounds may subsequently reorganize to form nitrogen and oxygen co-doped carbon-based materials comprising the SBMC at elevated temperatures. In addition to the nitrogen and oxygen co-doped carbon skeleton, these materials might contain defective carbon phases resulting from the removal of nitrogen and oxygen atoms. Yao et al. reported a simple method to remove nitrogen atoms from nitrogen-doped carbon to obtain a defective phase that showed excellent performance during the oxygen reduction reaction (ORR) and hydrogen evolution reaction
(HER). ${ }^{56} \mathrm{Li}$ and Zhang et al. considered that the reaction mechanism during acetylene hydrochlorination was the same as that associated with the ORR. ${ }^{17,20}$ Based on these prior reports, the SBMC-500 was calcined at a high temperature of $1050{ }^{\circ} \mathrm{C}$ under a nitrogen atmosphere for $2 \mathrm{~h}$, to produce a specimen termed SBMC-500/1050. As shown in Fig. 7a1, this material provided an acetylene conversion of $\sim 10 \%$ compared with $98 \%$ for the original catalyst. This contrast strongly indicates that the active sites in these SBMC for acetylene hydrochlorination were the nitrogen-doped carbon constructs, not the defective carbons without nitrogen atoms.

The effects of oxygen atoms on the catalytic activities of the SBMC were also assessed. Dai et al. elucidated the effect of oxygen-containing groups on the catalytic performances of nitrogen-doped graphene (N-G) and boron nitrogen co-doped graphene (B, N-G). ${ }^{18}$ Their work showed that the presence of oxygen atoms in the N-G and $\mathrm{B}, \mathrm{N}-\mathrm{G}$ catalysts decreased the adsorption of hydrogen chloride during the hydrochlorination of acetylene. According to the work, ${ }^{13}$ our own group prepared NAC and NAC-O catalysts using nitric acid. As shown in Fig. 7a2, the catalytic performance of the NAC-O during the hydrochlorination of acetylene was lower than that of the NAC catalyst because of the limited $\mathrm{HCl}$ adsorption onto active sites, consistent with the conclusion in ref. 18. Thus, the active sites on the SBMC are found in the nitrogen-doped carbon skeleton, not the oxygen-doped carbon skeleton or the defective carbon skeleton caused by the removal of nitrogen and oxygen atoms.

\section{The active sites for hydrogen chloride in the SBMC}

It is well known that $\mathrm{HgCl}_{2}$ and $\mathrm{AuCl}_{4}$ on $\mathrm{AC}$ provide active sites for acetylene and hydrogen chloride, respectively, during acetylene hydrochlorination. Thus, the active sites on the present nitrogen-doped carbon catalyst, which differ from one another, were also assessed. Dai et al. reported that pyridinic nitrogen atoms serve as catalytically active sites for hydrogen chloride, while carbon atoms are adsorption sites for acetylene. ${ }^{\mathbf{1 8 0} 20}$ Prior researchers did not perform separate studies concerning active sites for hydrogen chloride and acetylene, but rather focused on the overall effect of various types of nitrogen during the hydrochlorination of acetylene. ${ }^{17,50}$ We believe that the present analysis will therefore assist in designing improved nitrogendoped catalysts for this reaction. According to prior reports, ${ }^{\mathbf{1}}$ the chemical states of nitrogen atoms in nitrogen-doped

Table 2 Textural parameters of the SBMC

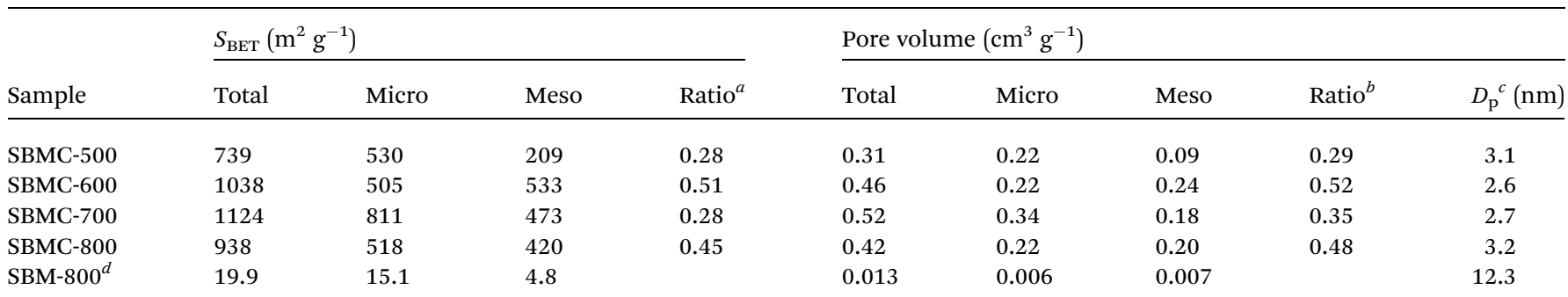

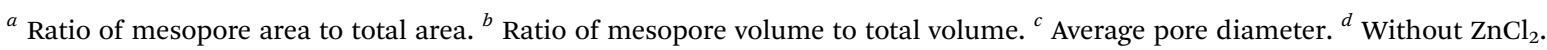


catalysts are closely correlated with the carbonization temperature. XPS spectra were acquired to probe the proportions and chemical states of $\mathrm{C}, \mathrm{N}, \mathrm{O}$ and $\mathrm{H}$ atoms in the SBMC materials. As shown in Fig. 7b, three characteristic peaks were observed at $\sim 284, \sim 400$ and $\sim 531 \mathrm{eV}$, assigned to $\mathrm{C} 1 \mathrm{~s}, \mathrm{~N} 1 \mathrm{~s}$ and $\mathrm{O} 1 \mathrm{~s}$ signals, respectively. With increases in the carbonization temperature, the proportion of nitrogen atom on the surface of the specimens gradually increased, from $\sim 2 \%$ at $250{ }^{\circ} \mathrm{C}$ to $\sim 7.5 \%$ at $700-800{ }^{\circ} \mathrm{C}$, confirming that high temperatures favour the migration of nitrogen atoms from the bulk of the SBMC and the removal of $\mathrm{H}$ and $\mathrm{O}$ atoms. Furthermore, elevated temperatures obviously resulted in changes in the chemical states of nitrogen atoms (see Fig. 7c). Following treatment at $250{ }^{\circ} \mathrm{C}$, only one characteristic peak, assigned to pyrrole $\mathrm{N}\left(\mathrm{C}_{2} \mathrm{NH}\right)$ was observed in the spectrum. When the temperature was increased to $300{ }^{\circ} \mathrm{C}$, some of this $\mathrm{N}$ was converted to pyridinic $\mathrm{N}\left(\mathrm{C}_{2} \mathrm{~N}\right)$, giving a proportion of $\sim 0.22 \%$. Following processing at $400{ }^{\circ} \mathrm{C}$, the pyrrole $\mathrm{N}\left(\mathrm{C}_{2} \mathrm{NH}\right)$ was converted to pyridinic $\mathrm{N}\left(\mathrm{C}_{2} \mathrm{~N}\right)$ to a greater extent $(\sim 1.52 \%)$. With treatment in the range of 500$800{ }^{\circ} \mathrm{C}$, the proportion of pyridinic $\mathrm{N}$ gradually increased, along with an increase in graphitic $\mathrm{N}\left(\mathrm{C}_{3} \mathrm{~N}\right)$ (Fig. 7d). As shown in Fig. 7e, pyridinic $\mathrm{N}$ proportions in the range of $0-1.52 \%$ increased the extent of acetylene conversion to greater than $88.6 \%$. This result suggests that pyridinic $\mathrm{N}$ atoms serve as critical active sites for acetylene hydrochlorination. As reported in ref. 1, pyridinic $\mathrm{N}$ contributes one $\mathrm{p}$ electron to the aromatic $\pi$ electron system and also has a lone electron pair in the plane of the carbon matrix that increases the electron donor properties of the catalyst. The introduction of pyridinic-type $\mathrm{N}$ species into the carbon network adds basicity, such that the material can be used as a solid base catalyst. Research has shown that hydrogen chloride is easily adsorbed onto pyridinic $\mathrm{N}$ based on theoretical calculations. ${ }^{20}$ To further demonstrate the function of pyridinic $\mathrm{N}$ atoms as active sites for hydrogen chloride, we prepared NAC loaded with $\mathrm{ZnCl}_{2}, \mathrm{CuCl}_{2}$ and $\mathrm{FeCl}_{3}$, termed $\mathrm{ZnCl}_{2} @ \mathrm{NAC}, \mathrm{CuCl}_{2} @ \mathrm{NAC}$ and $\mathrm{FeCl}_{3} @ \mathrm{NAC}$, respectively. As
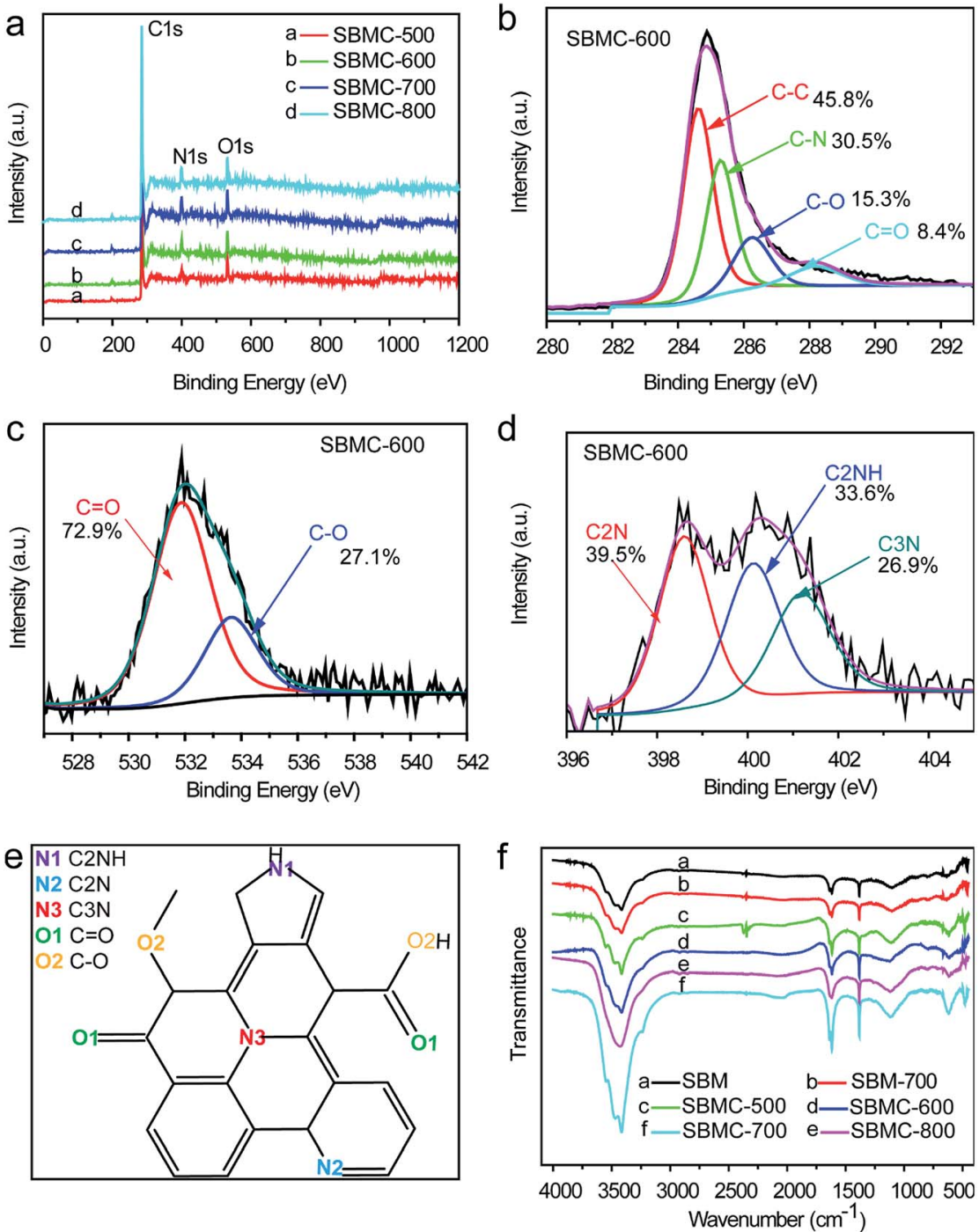

Fig. 4 (a) XPS survey spectra of the SBMC, the high-resolution (b) C 1s, (c) O 1s and (d) N 1s spectra of the SBMC-600, (e) the molecular structure of the SBMC and (f) the FTIR spectra of the SBMC. 

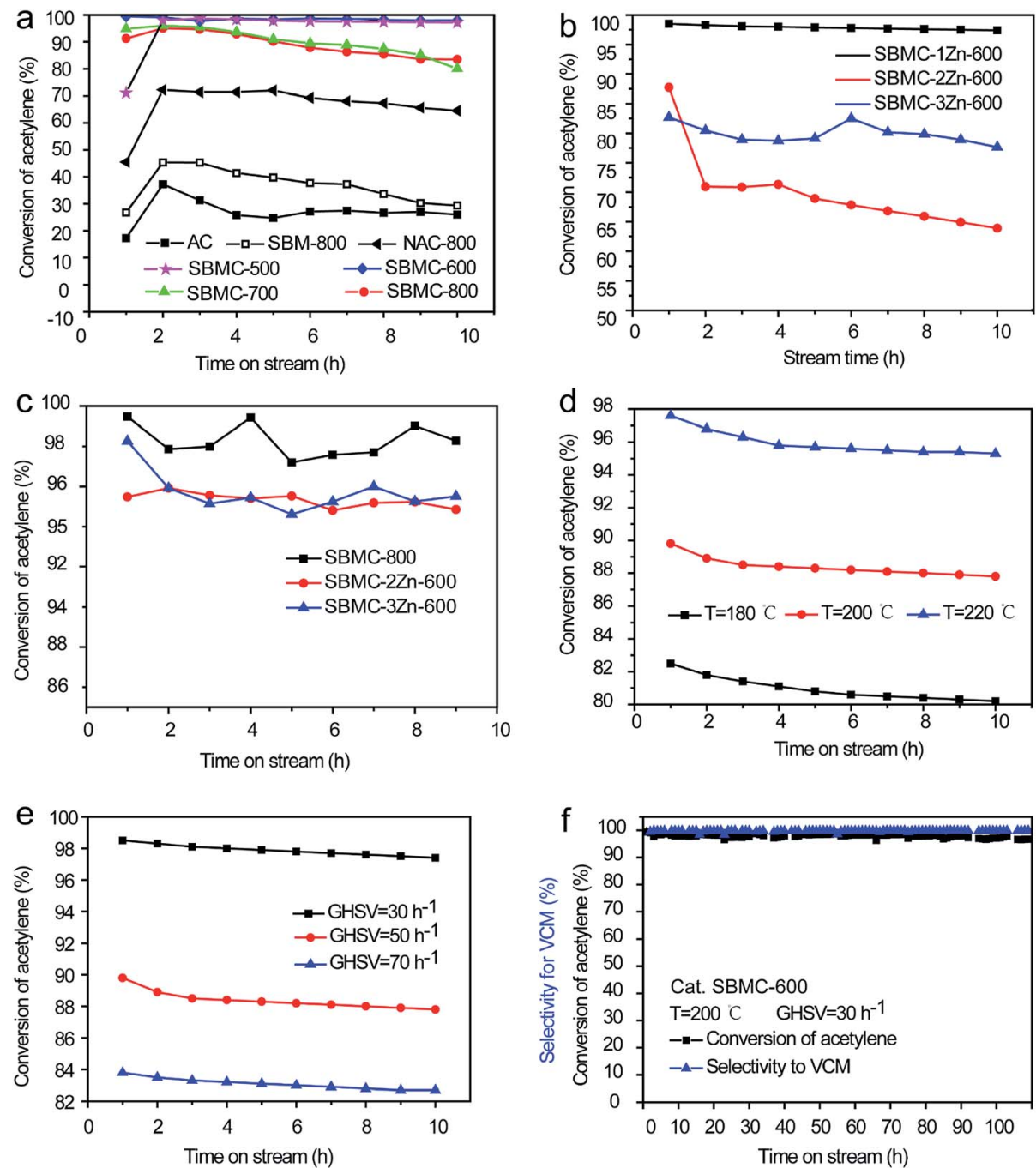

Fig. 5 Catalytic performances of the SBMC as functions of (a) carbonization temperature, (b) dosage of $\mathrm{ZnCl}_{2}$, (c) residual $\mathrm{ZnCl}$, (d) reaction temperature, (e) gas hourly space velocity (GHSV) of $\mathrm{C}_{2} \mathrm{H}_{2}$ and (f) the data from long-term stability testing of the SBM-600. Reactions were carried out at $200^{\circ} \mathrm{C}$, atmospheric pressure, a space velocity of $1.0 \mathrm{~mL} \mathrm{~g}^{-1} \mathrm{~min}^{-1}\left(\mathrm{GHSV}=30 \mathrm{~h}^{-1}\right.$ ) and HCl/ $\mathrm{C}_{2} \mathrm{H}_{2}=1.15 / 1.0$ (volume ratio) unless otherwise stated. The selectivity for VCM was above $98 \%$ at all times.

shown in Fig. 7f1, the acetylene conversions of the $\mathrm{ZnCl}_{2} @ \mathrm{NAC}$, $\mathrm{CuCl}_{2} @ \mathrm{NAC}$ and $\mathrm{FeCl}_{3} @ \mathrm{NAC}$ catalysts were all lower than that of NAC, because the Lewis acids occupied the pyridinic N sites of the NAC catalysts, inhibiting hydrogen chloride adsorption. These experimental results strongly suggest that the pyridinic $\mathrm{N}$ atoms were the active sites for the adsorption and activation of
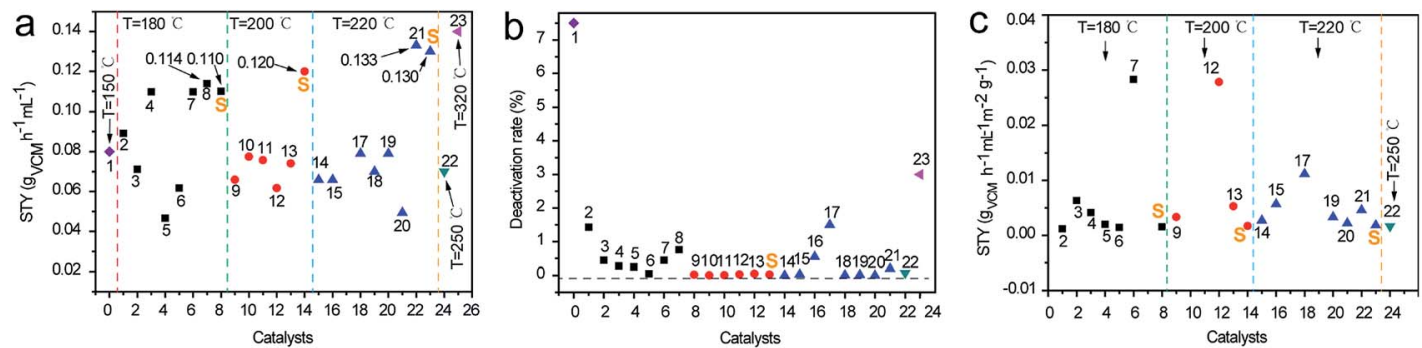

Fig. 6 Comparison of this work and the previous works of the metal-free catalysts. (a) The space-time yield (STY) of VCM; (b) the deactivation rate of catalysts; (c) the STY normalized by the surface area and nitrogen contents. The numbers represent the previous works of the metal-free catalysts in the literatures and $S$ denotes this work. $1,{ }^{18} 2,{ }^{20} 3,{ }^{17} 4,{ }^{16} 5,{ }^{44} 6,,^{13} 7,{ }^{45} 8,{ }^{46} 9,{ }^{2} 10,{ }^{15} 11,{ }^{47} 12,{ }^{48} 13,{ }^{49} 14,{ }^{50} 15,{ }^{51} 16,,^{22} 17,{ }^{23} 18,{ }^{52} 19,{ }^{53} 20,{ }^{54} 21,{ }^{24}$ $22,{ }^{19}$ and $23 . .^{55}$ 

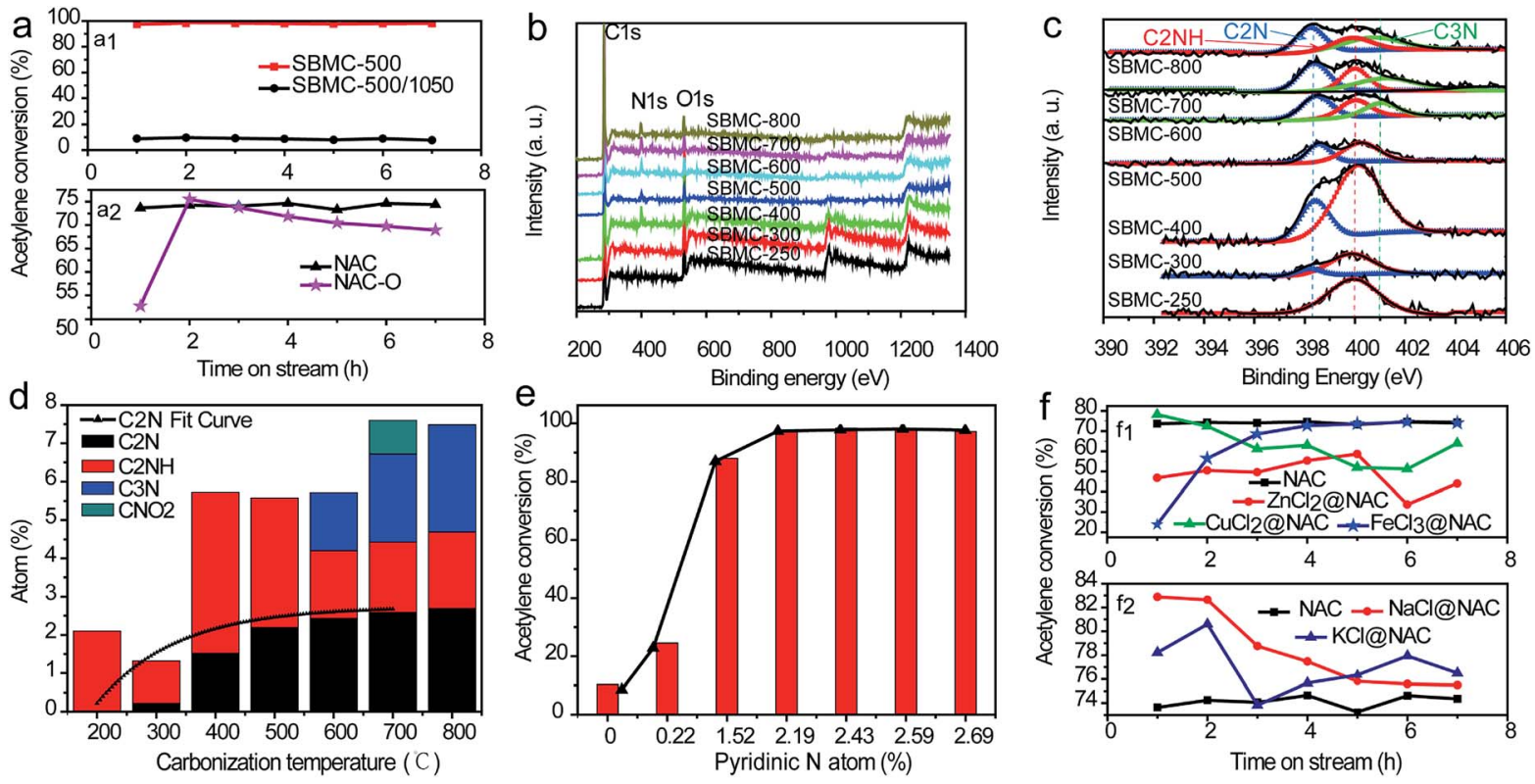

Fig. 7 (a1) Effects of nitrogen atoms on catalytic activity and (a2) effects of oxygen atoms on catalytic activity. (b) XPS spectra of SBMC obtained at different carbonization temperatures. (c) Nitrogen atom types obtained at various carbonization temperatures. (d) The proportion of $\mathrm{N}$ atoms in different chemical states at different carbonization temperatures. (e) Acetylene conversion over SBMC carbonized at various temperatures. (f) Effects of metal chlorides on catalytic activity.

hydrogen chloride, which is the rate-determining step for acetylene hydrochlorination. We also prepared two catalysts with alkali salts $(\mathrm{NaCl}$ and $\mathrm{KCl})$ loaded on NAC, denoted as NaCl@NAC and KCl@NAC. As shown in Fig. 7f2, the acetylene conversions of the NaCl@NAC and KCl@NAC were both higher than that of the bare NAC catalyst. This result shows that the alkali chlorides not only did not occupy the pyridinic $\mathrm{N}$ sites, but also provided active sites for adsorption of hydrogen chloride. Thus, the pyridinic $\mathrm{N}$ atoms in the nitrogen-doped carbon catalyst were the critical active sites for the adsorption and activation of hydrogen chloride during acetylene hydrochlorination. This information guided the further optimization of the nitrogen-doped carbon catalyst.

\section{The active sites for acetylene in the SBMC catalysts}

The active sites for acetylene in nitrogen-doped carbon catalysts during the hydrochlorination reaction remain unclear.
Similarly, there are evidently three types of $\mathrm{N}$ species coexisting in the present SBMC catalysts. To investigate the effects of each single type of $\mathrm{N}$ species on the activation of acetylene, two model catalysts were synthesized: $\mathrm{g}^{-} \mathrm{C}_{3} \mathrm{~N}_{4}$ and Ppy-400. The first represents an interesting synthetic carbon material with a total theoretical $\mathrm{N}$ content as high as $60.9 \%$ and an ideal structure containing only pyridinic and quaternary $\mathrm{N}$, with no pyrrolic $\mathrm{N}$ species. $^{2}$ The g- $\mathrm{C}_{3} \mathrm{~N}_{4}$ was synthesized with urea as the precursor at $500{ }^{\circ} \mathrm{C}$ in a muffle furnace over a $3 \mathrm{~h}$ time span. Ppy contains only pyrrolic $\mathrm{N}$, with no pyridinic and quaternary $\mathrm{N}$. The formation of Ppy- 400 with ppy as the precursor was performed at $400{ }^{\circ} \mathrm{C}$ in $\mathrm{N}_{2}$ for $2 \mathrm{~h}$. As shown in Fig. 8a, although it had not been activated by forming pores, the Ppy-400 exhibited superior catalytic performance during acetylene hydrochlorination, with an acetylene conversion of $86.2 \%$. This result clearly shows that pyrrolic $\mathrm{N}$ species served as the active sites and made a significant contribution to the activation of acetylene. In comparison,
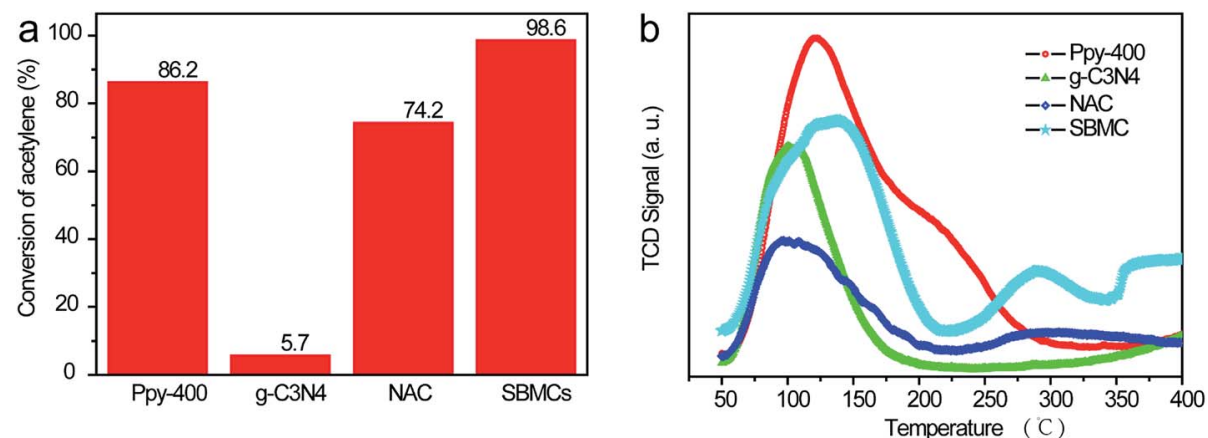

Fig. 8 (a) Temperature programmed desorption data for acetylene and (b) catalytic performances of the catalysts. Reaction conditions: $200{ }^{\circ} \mathrm{C}$, atmospheric pressure, space velocity of $1.0 \mathrm{~mL} \mathrm{~g}^{-1} \mathrm{~min}^{-1}, \mathrm{HCl} / \mathrm{C}_{2} \mathrm{H}_{2}=1.2 / 1.0$ (volume ratio). 
the $\mathrm{g}-\mathrm{C}_{3} \mathrm{~N}_{4}$ showed very poor activity for acetylene hydrochlorination, with a conversion of $5.7 \%$, implying that the pyridinic and quaternary $\mathrm{N}$ species were not active. Fig. 8a demonstrates that, although they had almost the same specific surface area of $\sim 1000 \mathrm{~m}^{2} \mathrm{~g}^{-1},{ }^{1}$ the SBMC exhibited excellent catalytic performance with $98.6 \%$ conversion. This value is much higher than that for the NAC (74.2\%) mainly because of the higher $\mathrm{N}$ content, especially pyrrolic $\mathrm{N}$ species, in the SBMC. This study thus demonstrates that the presence and quantity of pyrrolic $\mathrm{N}$ species determines the catalytic activity of the SBMC for acetylene.
TPD is an effective technique providing a direct comparison of the adsorption and activation of reactants on different catalysts. This method was thus used to further elucidate the active sites for acetylene on the SBMC. The desorption temperature in the TPD profiles reflects the binding strength of the adsorbed species with the catalyst surface, while the peak area correlates with the amount of adsorbed species. As shown in Fig. 8b, the desorption temperature of $\sim 121{ }^{\circ} \mathrm{C}$ and the peak area in the TPD- $\mathrm{C}_{2} \mathrm{H}_{2}$ profile of the Ppy-400 were much higher than that for the $\mathrm{g}-\mathrm{C}_{3} \mathrm{~N}_{4}$. These results clearly show that the pyrrolic $\mathrm{N}$ species were able to adsorb and activate acetylene (Fig. 8a). In comparison, the desorption temperature of $\sim 101{ }^{\circ} \mathrm{C}$ and the

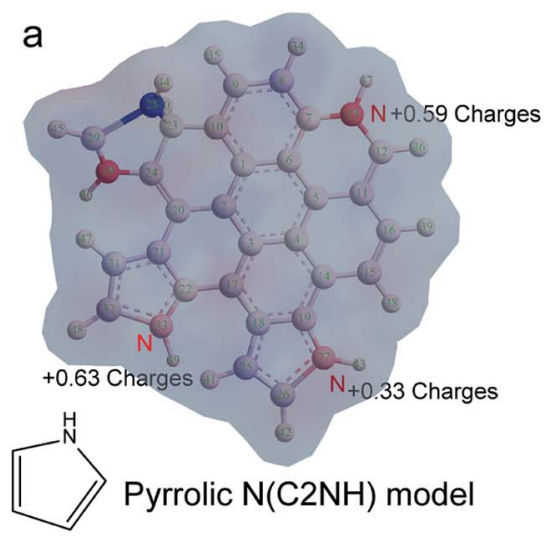

b

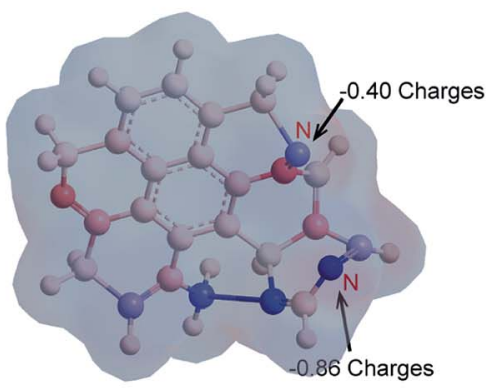

$\overbrace{n}$

Pyridinic N(C2N) model

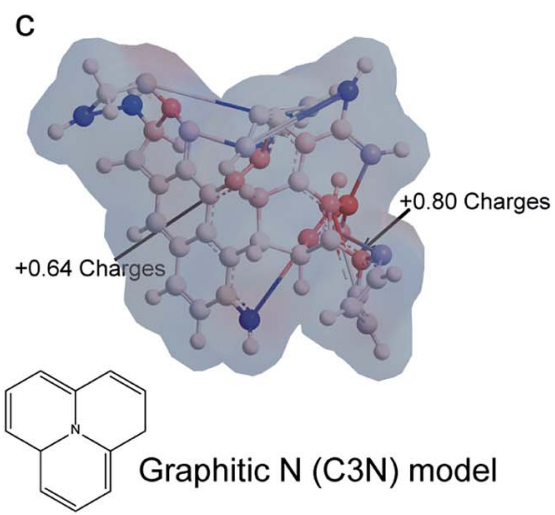

d

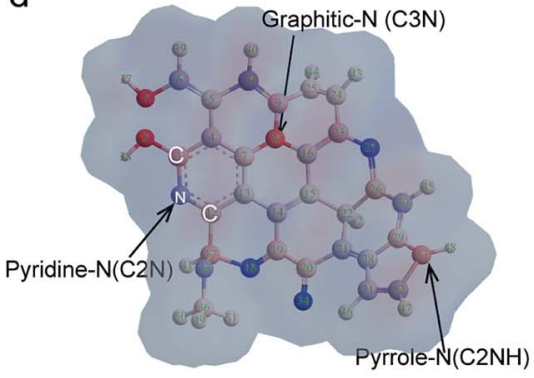

Surface model of SBMC

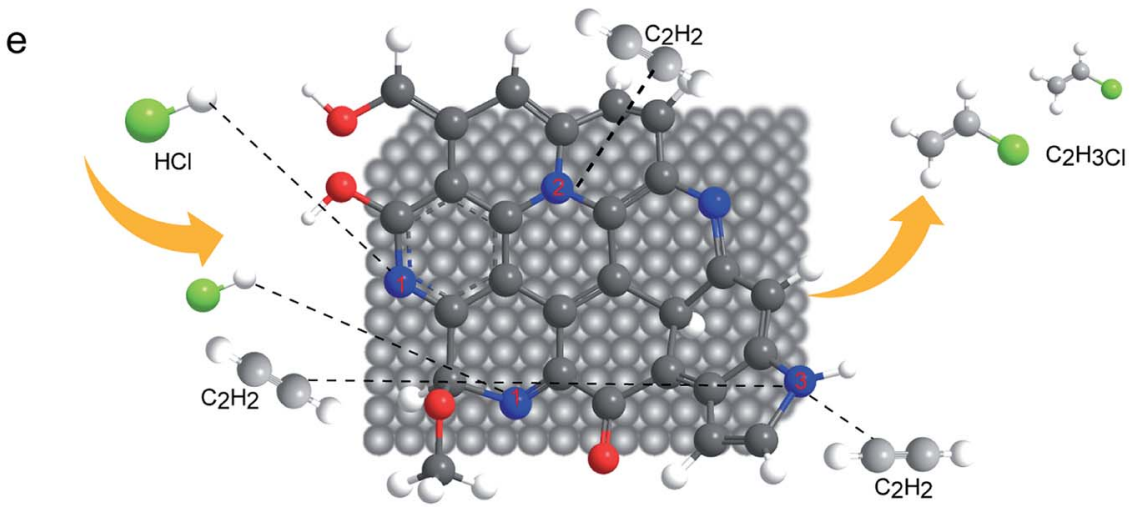

Fig. 9 A diagram showing the electron cloud distributions on the surfaces of model catalysts with only (a) pyrrolic $\mathrm{N}$ species, (b) pyridinic $\mathrm{N}$ species, (c) graphitic N species, (d) and with all three types of N species. (e) A diagram of the hydrochlorination of acetylene on the SBMC catalyst. 
peak area in the TPD- $\mathrm{C}_{2} \mathrm{H}_{2}$ profile of $\mathrm{g}-\mathrm{C}_{3} \mathrm{~N}_{4}$ were lower, indicating that carbon materials with pyridinic and quaternary $\mathrm{N}$ have less ability to adsorb acetylene than Ppy-400. However, although it had greater ability to adsorb acetylene than the NAC, the g- $\mathrm{C}_{3} \mathrm{~N}_{4}$ showed very poor catalytic performance (Fig. 8a). This result demonstrates that carbon materials with pyridinic and quaternary $\mathrm{N}$ species will adsorb but not activate acetylene. In fact, pyridinic $\mathrm{N}$ and acetylene both donate electron pairs, and thus pyridinic $\mathrm{N}$ species would not be expected to adsorb acetylene. The g- $\mathrm{C}_{3} \mathrm{~N}_{4}$ exhibited some ability to adsorb acetylene (Fig. 8b), attributed to the quaternary $\mathrm{N}$ species it contained. Thus, the three types of $\mathrm{N}$ species contributed to the activation of acetylene in the order: pyrrolic $\mathrm{N}>$ quaternary $\mathrm{N}>$ pyridinic $\mathrm{N}$. The pyrrolic $\mathrm{N}$ species were therefore the critical active sites for the adsorption and activation of acetylene. As shown in Fig. 8b, a comparison of the TPD profiles of the SBMC and NAC reveals that the former exhibit higher adsorption and activation of acetylene, attributed to the higher concentration of pyrrolic $\mathrm{N}$ species in the SBMC. These data are in keeping with the results in Fig. 8a. A comparison of the TPD profiles for the SBMC and Ppy-400 indicates that the Ppy-400 exhibited greater adsorption and activation of acetylene as a result of a higher level of pyrrolic $\mathrm{N}$ species. Even so, although it showed many more active sites for acetylene, the Ppy-400 had lower catalytic performance than the SBMC. This result is attributed to the lower amount of pyridinic $\mathrm{N}$ species in the Ppy-400. The pyridinic $\mathrm{N}$ species adsorbed and activated hydrogen chloride, which was the rate-limiting step for acetylene hydrochlorination over the SBMC catalyst. Consequently, this result further demonstrates that there were two active sites in the SBMC, pyridinic $\mathrm{N}$ and pyrrolic $\mathrm{N}$, acting as the active sites for hydrogen chloride and acetylene, respectively.

In a typical catalytic reaction, the electron distribution at the active sites polarizes the reactant molecules on the surface and reduces the reaction activation energy in order to increase the reaction rate. To further investigate the nature of the three types of $\mathrm{N}$ species on the SBMC with regard to activating acetylene, the electron distributions of the catalysts are simulated in Fig. 9. In Fig. 9a, the pyrrolic N species show large positive charges. During the acetylene hydrochlorination, acetylene is the electron donor, and thus it tends to adsorb on the pyrrolic $\mathrm{N}$ model catalyst in keeping with the TPD- $\mathrm{C}_{2} \mathrm{H}_{2}$ data and the catalytic performance of the ppy-400 (Fig. 8). Fig. 8b demonstrates that the pyridinic $\mathrm{N}$ species are negatively charged. Hydrogen chloride will be readily polarized by the negative charge cloud, and thus it will be adsorbed onto pyridinic $\mathrm{N}$ species. This explains why pyridinic $\mathrm{N}$ species are the active sites for hydrogen chloride. As shown in Fig. 9c, there is a positive charge on each graphitic $\mathrm{N}$, and therefore these tend to adsorb acetylene, in agreement with the TPD- $\mathrm{C}_{2} \mathrm{H}_{2}$ results for $\mathrm{g}-\mathrm{C}_{3} \mathrm{~N}_{4}$ (Fig. 8b). However, in a catalytic reaction, the adsorption of reactant molecules is not the same as activation. Thus, the $\mathrm{g}-\mathrm{C}_{3} \mathrm{~N}_{4}$ catalyst demonstrated very poor catalytic performance during acetylene hydrochlorination (Fig. 8a). The theoretical electron cloud distributions on the model catalysts were highly consistent with the TPD- $\mathrm{C}_{2} \mathrm{H}_{2}$ data and catalytic performances of these materials (Fig. 8). The study of the electron distributions confirmed that the different $\mathrm{N}$ species can activate acetylene, which explains the performance of the N-doped carbon catalyst and is in agreement with previous reports from Hutchings' group. Hutchings determined that the catalytic activity of a metal chloride for acetylene gradually increased with the metal ion potential. ${ }^{10,57}$ Schematic diagrams of the three types of $\mathrm{N}$ species distribution on the SBMC catalyst are presented in Fig. 9d while a diagram of the acetylene hydrochlorination mechanism on the SBMC catalyst is shown in Fig. 9e. Initially, the hydrogen chloride molecule is polarized and adsorbed onto the pyridinic $\mathrm{N}$ species. In addition, acetylene is adsorbed onto the positively charged sites such as pyrrolic $\mathrm{N}$ and then polarized. Secondly, the polarized hydrogen chloride reacts with the polarized acetylene to synthesize the VCM. Finally, the VCM leaves to complete the hydrochlorination.

\section{Conclusions}

This work produced a unique, green, low-cost and metal-free catalyst via the carbonization of SBM with $\mathrm{ZnCl}_{2}$ at $500-$ $700{ }^{\circ} \mathrm{C}$. These materials exhibited superior catalytic performance during acetylene hydrochlorination over a time span of $110 \mathrm{~h}$, with an initial acetylene conversion of over $99 \%$ and $98 \%$ selectivity for VCM at $200{ }^{\circ} \mathrm{C}$. XPS, TPD and catalytic activity evaluations established that pyridinic and pyrrolic species represent the active sites for hydrogen chloride and for acetylene, respectively. Charge calculations based on model catalysts indicated that the activity of the pyrrolic species contributed to the potential of the SBMC catalysts. Investigation of the mechanism for acetylene hydrochlorination over these materials established that the $\mathrm{N}$-doped catalyst had two different active sites that worked to adsorb and activate hydrogen chloride and acetylene, in contrast to metal chloride catalysts such as $\mathrm{HgCl}_{2}$. These SBMC have the potential to serve as substitutes for $\mathrm{HgCl}_{2} /$ $\mathrm{AC}$ as catalysts for VCM production. The results of this work also suggest the feasibility of using biomass as a feedstock to synthesize functional carbon materials for acetylene hydrochlorination. The mechanistic details reported herein also suggest new approaches to further optimization, specifically, by increasing the concentration of pyridinic moieties in order to promote the adsorption and activation of hydrogen chloride. Finally, these results are expected to encourage further experimentation to improve N-doped catalysts in order to enhance the adsorption and activation of acetylene by increasing the level of pyrrolic species and/or doping with additional heteroatoms.

\section{Experimental}

\section{Materials}

AC (neutral, coal-based carbon) was purchased from the Ningxia Guanghua Activated Carbon Co., Ltd. SBM was obtained from the Yihai Kerry Co., Ltd. The reagents, including $\mathrm{ZnCl}_{2}$ (AR), acrylamide (AR) and concentrated hydrochloric acid (>36\%, AR) were purchased from the Taitan Technology Co., Ltd. The gases, including acetylene (99.99\%) and nitrogen (99.99\%), were purchased from the Shanghai Lvming Gas Co., Ltd. Hydrogen chloride (99.998\%) was purchased from the Beijing Lvling Gas Co., Ltd. 


\section{Catalyst preparation}

SBM was employed as the source of carbon, nitrogen and oxygen, with $\mathrm{ZnCl}_{2}$ as the activation agent. SBMC was prepared by first drying the SBM at $80^{\circ} \mathrm{C}$ for $24 \mathrm{~h}$, followed by grinding to a 20-40 mesh particle size. The SBM was subsequently impregnated by immersion in a $\mathrm{ZnCl}_{2}$ solution, using the incipient wetness impregnation technique, with an $\mathrm{ZnCl}_{2} / \mathrm{SBM}$ mass ratio of approximately $1: 1$. The SBM was subsequently dried at $120^{\circ} \mathrm{C}$ for $6-10 \mathrm{~h}$ and the dried material was calcined at $500,600,700$ or $800{ }^{\circ} \mathrm{C}$ to generate nitrogen-doped porous carbon or SBMC. The product was obtained by washing the crude material to remove excess $\mathrm{ZnCl}_{2}$, using $2 \mathrm{~N} \mathrm{HCl}$, deionized water and ethanol. The resulting materials were termed SBMC500, SBMC-600, SBMC-700 and SBMC-800 according to the carbonization temperature. Similarly, the term SBMC- $x \mathbf{Z n C l}_{2}$ 600 refers to a material in which $x$ is the $\mathrm{ZnCl}_{2} / \mathrm{SBM}$ ratio. NAC catalysts were prepared by an incipient wetness impregnation technique using $\mathrm{AC}$ as the carrier and acrylamide as the $\mathrm{N}$ precursor. The mixture of AC and acrylamide was dried at $120{ }^{\circ} \mathrm{C}$ for $6-12 \mathrm{~h}$ after which the dried mixture was calcined at $650{ }^{\circ} \mathrm{C}$ for $4 \mathrm{~h}$ under $\mathrm{N}_{2}$ to obtain the final product. $\mathrm{M}_{x} \mathrm{Cl}_{y} @ \mathrm{NAC}$ catalysts were prepared using metal chlorides $\left(\mathrm{M}_{x} \mathrm{Cl}_{y}\right)$ as the active components and NAC as the carrier, employing a simple incipient wetness impregnation technique.

\section{Catalyst characterization}

Brunauer-Emmett-Teller (BET) surface area data were collected by obtaining nitrogen adsorption isotherms at $77 \mathrm{~K}$ using a Micromeritics ASAP 2020 analyser (ASAP 2020, Micromeritics Company, USA). Wide-angle XRD patterns $\left(10^{\circ}-90^{\circ}\right.$ over $\left.2 \mathrm{~h}\right)$ were collected using a Bruker D8 Advanced X-ray diffractometer with $\mathrm{Cu} \mathrm{K} \alpha$ radiation $(k=1.5406 \AA$ ) at $40 \mathrm{kV}$ and $40 \mathrm{~mA}$ (Bruker D8, Brucker Company, Germany). TEM images were acquired with a JEM 2010 electron microscope at an accelerating voltage of $200 \mathrm{kV}$ to examine sample morphologies (JEM-2010, JEOL Company, Japan), and field emission scanning electron microscope (S-4800, Hitachi Company, Japan). XPS data were generated using an Axis Ultra spectrometer with monochromatized Al $\mathrm{K} \alpha \mathrm{X}$-ray radiation as the excitation source $(225 \mathrm{~W})$ (EscaLab 250Xi, Thermo Fisher Scientific Company, USA). Raman microspectroscopy was performed with a Renishaw InVia unit having an Ar ion laser (inVia reflex, Renishaw Company, UK). TGA data were acquired using a TA instrument, operating under air at a flow rate of $100 \mathrm{~mL} \mathrm{~min}^{-1}$. The temperature of each sample was increased from 30 to $800{ }^{\circ} \mathrm{C}$ at a heating rate of $10{ }^{\circ} \mathrm{C} \min ^{-1}$ (SDT Q600, TA Company, USA). TPD trials were carried out with a Micromeritics ASAP 2720 instrument with a temperature ramp of $40-650{ }^{\circ} \mathrm{C}$, a ramp rate of $10{ }^{\circ} \mathrm{C} \mathrm{min}{ }^{-1}$

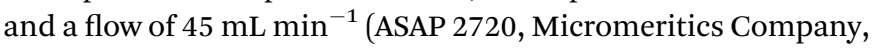
USA).

\section{Catalytic reactions}

Catalytic performance was evaluated in a fixed-bed reactor (i.d. $6 \mathrm{~mm}$ ), the temperature of which was regulated using a temperature controller (Y-Feng, Yefeng Company, China). In each trial, a $1.0 \mathrm{~g}$ sample of catalyst was placed in the reactor and nitrogen was used to purge water and air before starting the reaction. Hydrogen chloride gas was passed through the reactor at a flow rate of $20 \mathrm{~mL} \mathrm{~min}{ }^{-1}$ to activate the catalyst. Thereafter, acetylene $\left(1.0 \mathrm{~mL} \mathrm{~min}^{-1}\right)$ and hydrogen chloride $\left(1.15 \mathrm{~mL} \mathrm{~min}^{-1}\right)$ were fed through the heated reactor at a gas hourly space velocity (GHSV) of $30 \mathrm{~h}^{-1}$ and a reaction temperature of $200{ }^{\circ} \mathrm{C}$. The reaction products were analysed by gas chromatography (GC-2014, Shimadzu Company, Japan).

The conversion of acetylene was calculated as:

$$
X_{\mathrm{A}}=\left(1-\varnothing_{\mathrm{A}}\right) \times 100 \% ; S_{\mathrm{V}}=\left(\frac{\varnothing_{\mathrm{V}}}{1-\varnothing_{\mathrm{A}}}\right) \times 100 \%,
$$

where $X_{\mathrm{A}}$ is the conversion of acetylene, $S_{\mathrm{V}}$ is the selectivity for VCM, $\varnothing_{\mathrm{A}}$ is the ratio of the peak area of acetylene and $\varnothing_{\mathrm{V}}$ is the ratio of the peak area of VCM.

The space-time yield (STY) of VCM was calculated as in the following equation,

$$
\mathrm{STY}=\frac{n_{\mathrm{A}} \times Y_{\mathrm{VCM}} \times M_{\mathrm{VCM}}}{V_{\text {Cat. }} \times t_{\mathrm{R} .}}\left(g_{\mathrm{VCM}} \mathrm{h}^{-1} \mathrm{~mL}^{-1}\right)
$$

where $n_{\mathrm{A}}$ represents the moles of acetylene in the raw gas (mol), $Y_{\mathrm{VCM}}$ represents the yield of VCM, $M_{\mathrm{VCM}}$ represents the molar mass of VCM (62.5 $\left.\mathrm{g} \mathrm{mol}^{-1}\right), V_{\text {Cat. }}$ represents the volume of catalyst in reactor $(\mathrm{mL}), t_{\mathrm{R}}$ represents reaction time $(\mathrm{h})$.

\section{Conflicts of interest}

There are no conflicts to declare.

\section{Acknowledgements}

This work was supported by the National Natural Science Foundation of China (grant no. 21372234) and by the Key Research Program of the Chinese Academy of Sciences (grant no. ZDRW-CN-2016-1).

\section{References}

1 Z. Shen, H. Zhao, Y. Liu, Z. Kan, P. Xing, J. Zhong and B. Jiang, React. Chem. Eng., 2018, 3, 34-40.

2 X. Li, X. Pan, L. Yu, P. Ren, X. Wu, L. Sun, F. Jiao and X. Bao, Nat. Commun., 2014, 5, 3688.

3 P. Johnston, N. Carthey and G. J. Hutchings, J. Am. Chem. Soc., 2015, 137, 14548-14557.

4 A. J. Poulain and T. Barkay, Science, 2013, 339, 1280-1281. 5 J. M. Parks, A. Johs, M. Podar, R. Bridou, R. A. Hurt, Jr, S. D. Smith, S. J. Tomanicek, Y. Qian, S. D. Brown, C. C. Brandt, A. V. Palumbo, J. C. Smith, J. D. Wall, D. A. Elias and L. Liang, Science, 2013, 339, 1332-1335.

6 D. P. Krabbenhoft and E. M. Sunderland, Science, 2013, 341, 1457-1458.

7 D. Normile, Sciences, 2013, 341, 1446-1447.

8 J. Qiu, Nature, 2013, 493, 144-145.

9 U. N. E. Programme, http:/www.mercuryconvention.org/.

10 G. J. Hutchings, J. Catal., 1985, 96, 292-295. 
11 M. Conte, A. F. Carley, G. Attard, A. A. Herzing, C. J. Kiely and G. J. Hutchings, J. Catal., 2008, 257, 190-198.

12 M. Conte, A. F. Carley, C. Heirene, D. J. Willock, P. Johnston, A. A. Herzing, C. J. Kiely and G. J. Hutchings, J. Catal., 2007, 250, 231-239.

13 T. T. Zhang, J. Zhao, J. T. Xu, J. H. Xu, X. X. Di and X. N. Li, Chin. J. Chem. Eng., 2016, 24, 484-490.

14 J. Wang, F. Zhao, C. L. Zhang, L. H. Kang and M. Y. Zhu, Appl. Catal., A, 2018, 549, 68-75.

15 P. Li, H. B. Li, X. L. Pan, K. Tie, T. T. Cui, M. Z. Ding and X. H. Bao, ACS Catal., 2017, 7, 8572-8577.

16 X. Y. Li, J. L. Zhang and W. Li, J. Ind. Eng. Chem., 2016, 44, 146-154.

17 C. L. Zhang, L. H. Kang, M. Y. Zhu and B. Dai, RSC Adv., 2015, 5, 7461-7468.

18 B. Dai, K. Chen, Y. Wang, L. H. Kang and M. Y. Zhu, ACS Catal., 2015, 5, 2541-2547.

19 X. Wang, B. Dai, Y. Wang and F. Yu, ChemCatChem, 2014, 6, 2339-2344.

20 X. Li, Y. Wang, L. Kang, M. Zhu and B. Dai, J. Catal., 2014, 311, 288-294.

21 R. H. Lin, S. K. Kaiser, R. Hauert and J. Perez-Ramirez, ACS Catal., 2018, 8, 1114-1121.

22 W. Liu, M. Zhu and B. Dai, New J. Chem., 2018, 42, 2013120136.

23 J. Wang, W. Gong, M. Zhu and B. Dai, Appl. Catal., A, 2018, 564, 72-78.

24 F. Lu, Y. Lu, M. Zhu and B. Dai, ChemistrySelect, 2020, 5, 878885.

25 X. Zhou, M. Zhu and L. Kang, Catalysts, 2019, 9, 808-890.

26 Z. Zhao, B. Wang, Y. Yue, G. Sheng, H. Lai, S. Wang, L. Yu, Q. Zhang, F. Feng, Z. Hu and X. Li, J. Catal., 2019, 373, 240-249.

27 J. Qian, X. Wang, L. Chai, L. Liang, T. Li, Y. Hu and S. Huang, Cryst. Growth Des., 2018, 18(4), 2358-2364.

28 L. Chai, L. Zhang, X. Wang, L. Xu, C. Han, T. Li, Y. Hu, J. Qian and S. Huang, Carbon, 2019, 146, 248-256.

29 X. Y. Li, J. L. Zhang, Y. Han, M. Y. Zhu, S. S. Shang and W. Li, J. Mater. Sci., 2018, 53, 4913-4926.

30 S. L. Chao, F. Zou, F. F. Wan, X. B. Dong, Y. L. Wang, Y. X. Wang, Q. X. Guan, G. C. Wang and W. Li, Sci. Rep., 2017, 7, 39789-39795.

31 Z. Chen, Y. Chen, S. Chao, X. Dong, W. Chen, J. Luo, C. Liu, D. Wang, C. Chen, W. Li, J. Li and Y. Li, ACS Catal., 2020, 10, 1865-1870.

32 F. Pach and F. Nagel, Aquacult. Nutr., 2018, 24, 666-672.

33 X. Zhou, P. L. Wang, Y. G. Zhang, L. L. Wang, L. T. Zhang, L. Zhang, L. Xu and L. Liu, J. Mater. Chem. A, 2017, 5, 12958-12968.
34 Y. Li, Q. Du, X. Wang, P. Zhang, D. Wang, Z. Wang and Y. Xia, J. Hazard. Mater., 2010, 183, 583-589.

35 F. Boudrahem, F. Aissani-Benissad and H. Aït-Amar, J. Environ. Manage., 2009, 90, 3031-3039.

36 M. A. Lillo-Ródenas, J. Juan-Juan, D. Cazorla-Amorós and A. Linares-Solano, Carbon, 2004, 42, 1371-1375.

37 M. A. Lillo-Rodenas, D. Cazorla-Amoros and A. LinaresSolan, Carbon, 2003, 41, 267-275.

38 J. Tan, H. Chen, Y. Gao and H. Li, Electrochim. Acta, 2015, 178, 144-152.

39 L. Wang, Z. Gao, J. Chang, X. Liu, D. Wu, F. Xu, Y. Guo and K. Jiang, ACS Appl. Mater. Interfaces, 2015, 7, 20234-20244.

40 A. Sadezky, H. Muckenhuber, H. Grothe, R. Niessner and U. Pöschl, Carbon, 2005, 43, 1731-1742.

41 J. Gong, H. Lin, M. Antonietti and J. Yuan, J. Mater. Chem. A, 2016, 4, 7313-7321.

42 B. C. Man, H. Y. Zhang, J. L. Zhang, X. Li, N. Xu, H. Dai, M. Y. Zhu and B. Dai, RSC Adv., 2017, 7, 23742-23750.

43 H. Zhang, Y. Wang, D. Wang, Y. Li, X. Liu, P. Liu, H. Yang, T. An, Z. Tang and H. Zhao, Small, 2014, 10, 3371-3378.

44 Y. Yang, G. J. Lan, X. L. Wang and Y. Li, Chin. J. Catal., 2016, 37, 1242-1248.

45 J. Wang, F. Zhao, C. Zhang, L. Kang and M. Zhu, Appl. Catal., $A, 2018,549,68-75$.

46 Y. Nian, J. Zhang, X. Li, Y. Wang, W. Li, P. D Kolubah and Y. Han, Phys. Chem. Chem. Phys., 2019, 21, 7635-7644.

47 X. Li, Y. Nian, S. Shang, H. Zhang, J. Zhang, Y. Han and W. Li, Catal. Sci. Technol., 2019, 9, 188-198.

48 X. Qiao, C. Zhao, Z. Zhou, Q. Guan and W. Li, ACS Sustainable Chem. Eng., 2019, 7, 17979-17989.

49 X. Qiao, Z. Zhou, X. Liu, C. Zhao, Q. Guan and W. Li, Catal. Sci. Technol., 2019, 9, 3753-3762.

50 G. Lan, Y. Wang, Y. Qiu, X. Wang, J. Liang, W. Han, H. Tang, H. Liu, J. Liu and Y. Li, Chem. Commun., 2018, 54, 623-626.

51 X. Li, J. Zhang, Y. Han, M. Zhu, S. Shang and W. Li, J. Mater. Sci., 2018, 53, 4913-4926.

52 G. Lan, Y. Qiu, J. Fan, X. Wang, H. Tang, W. Han, H. Liu, H. Liu, S. Song and Y. Li, Chem. Commun., 2019, 55, 14301433.

53 S. Mei, J. Gu, T. Ma, X. Li, Y. Hu, W. Li, J. Zhang and Y. Han, Chem. Eng. J., 2019, 371, 118-129.

54 Y. Qiu, S. Ali, G. Lan, H. Tong, J. Fan, H. Liu, B. Li, W. Han, H. Tang, H. Liu and Y. Li, Carbon, 2019, 146, 406-412.

55 Z. J. Song, G. Y. Liu, D. W. He, X. D. Pang, Y. S. Tong, Y. Q. Wu, D. H. Yuan, Z. M. Liu and Y. P. Xu, Green Chem., 2016, 18, 5994-5998.

56 X. Yan, Y. Jia, T. Odedairo, X. Zhao, Z. Jin, Z. Zhu and X. Yao, Chem. Commun., 2016, 52, 8156-8159.

57 G. J. Hutchings and D. T. Grady, Appl. Catal., 1985, 17, 155160. 